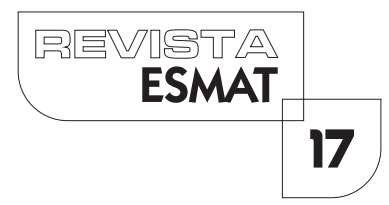

\title{
LOS DERECHOS DE LA NATURALEZA EN LA CONSTITUCIÓN ECUATORIANA DEL 2008: ALCANCE, FUNDAMENTOS $Y$ RELACIÓN CON LOS DERECHOS HUMANOS
}

THE RIGHTS OF NATURE IN THE ECUADORIAN CONSTITUTION OF 2008: SCOPE, FOUNDATIONS AND RELATIONSHIP WITH HUMAN RIGHTS

\section{Farith Simon Campaña'}

Doctor en Derecho por la Universidad de Salamanca, Doctor en Jurisprudencia por la Pontificia Universidad Católica del Ecuador, Abogado. Profesor titular principal del Colegio de Jurisprudencia de la Universidad San Francisco de Quito.

\section{RESUMEN}

El otorgamiento de derechos a la naturaleza ("la pachamama") en la Constitución ecuatoriana del 2008 se ha presentado como una innovación trascendental en el mundo jurídico para la protección del planeta Tierra. Esta se explica como una confluencia de cosmovisiones distintas (la comprensión indígena sobre la naturaleza y la teoría occidental de la Gaia de James Lovelock) que dio paso a una comprensión de la relación ser humano-naturaleza, dejando atrás un antropocentrismo reflejo claro de la modernidad y ha dado paso al biocentrismo. Este trabajo explora las justificaciones que se han dado para ese reconocimiento, particularmente aquellas que aseguran que la cosmovisión indígena es la que llevó a esta declaración constitucional; la forma en que la jurisprudencia constitucional ecuatoriana ha tratado el tema y lasposibles relaciones que se dan con los derechos humanos.

PALABRAS CLAVE: Derechos de la naturaleza; constitución ecuatoriana, pachamama, Gaia, antropocentrismo, biocentrismo, derechos humanos.

\section{ABSTRACT}

The recognition of rights to nature ("pachamama") in the Ecuadorian Constitution of 2008 has been presented as a transcendental innovation in the legal world for the protection of the planet Earth. This has been presented as a confluence of different worldviews (the indigenous understanding of nature and the theory of Gaia by James Lovelock) that gave way to an understanding of the human-nature relationship, leaving behind an anthropocentrism a clear reflection of modernity and has given way

I Doctor en Derecho por la Universidad de Salamanca, Doctor en Jurisprudencia por la Pontificia Universidad Católica del Ecuador, Abogado. Profesor titular principal del Colegio de Jurisprudencia de la Universidad San Francisco de Quito. 
to biocentrism. This paper explores the justifications that have been given for this recognition, particularly those explanations that ensure that the indigenous worldview is what led to this constitutional declaration in Ecuador; the way in which the jurisprudence of the Constitutional Court of Ecuador has dealt with the issue and the relationship with human rights.

KEYWORDS: Rights of nature; Ecuadorian constitution, pachamama, Gaia, anthropocentrism, biocentrism, human rights.

\section{INTRODUCCIÓN}

\section{El posible colapso ambiental y las respuestas desde el derecho}

El anunciado colapso ambiental se considera una amenaza global que pone en riesgo la existencia misma de la humanidad, se requieren de acciones urgentes y coordinadas para enfrentarlo. Los seres humanos "estamos alterando el delicado equilibrio ecológico formado en millones de años". El Homo sapiens durante miles de años "se ha comportado como un asesino ecológico en serie; ahora está transformándose en un asesino ecológico en masa", de no hacer nada "...no solo llegará a aniquilar un gran porcentaje de todos los seres vivos, sino que también podrían debilitarse los cimientos de la civilización humana".

Excepto por los escépticos del cambio climático representados por un sector de conservadores y libertarios ${ }^{3} c o n$ gran poder ${ }^{4}$, existe un amplio consenso cientííco sobre la grave catástrofe que enfrentamos sino logramos disminuir las emisiones de gases de efecto invernadero en los próximos 20 años, con solo $2{ }^{\circ} \mathrm{C}$ más de temperatura media global, que en algunos lugares como en África serían unos $3^{\circ} \mathrm{C}^{5}$, lo que "provocará la expansión de los desiertos, la desaparición de los casquetes polares, el aumento del nivel de los océanos y una mayor incidencia de acontecimientos meteorológicos extremos, como huracanes y tifones. Estos cambios alterarán a su vez la producción agrícola, inundarán ciudades, gran parte del mundo se vuelva inhabitable y que cientos de millones de refugiados busquen nuevos hogares ${ }^{6}$.

2 Harari, Yuval Noah, 2 I lecciones para el siglo XXI, Debate, Barcelona, 20 I8, p. 138.

3 Ver http://niskanencenter.org/wp-content/uploads/20 I5/03/The-Conservative-Case-for-a-Carbon-Taxl.pdf.

4 Gunther, Marc, Warming, Climate Converts: The Conservatives Who Are Switching Sides on, Yale Enviroment 360. Disponible https://e360.yale.edu/features/climate-converts-the-conservatives-who-are-switching-sides-on-climate-change,

5 Bassey, Nnimmo, iLa tecnología no puede salvarnos!, entrevista de Daniel Kopp de agosto de 20 I8. Disponible en https://www.ipg-journal.de/interviews/artikel/technologie-kann-uns-nicht-retten-2893/.

6 Harari, op. cit., p. 139. 
DinahShelton ${ }^{7}$ identifica que el uso de diferentes clases de medidas para la protección del ambiente a las cuales agrupa en cinco categorías: el derecho de daños basado en el derecho de propiedad; las normas de derecho medioambiental; el mercado; el derecho constitucional o derecho internacional de los derechos humanos; y, la personificación de la naturaleza. El Ecuador, en su Constitución del año 2008, es el primer país -y el único hasta el momento- en darle a la naturaleza la condición de sujeto de derechos y atribuirle derechos específicos a nivel constitucional. En otros países esto se ha hechoa nivellegal, como en el caso de Bolivia o Nueva Zelanda, a nivel jurisprudencial, como en la India o en Colombia, por medio de regulaciones de alcance municipal o cantonal, como en los Estados Unidos.

Esta idea de personalización de la naturaleza no es nueva, pero en estos años ha recibido una atención adicional, este trabajo presenta una visión global de lo dispuesto en la Constitución ecuatoriana, revisa los diferentes discursos justificatorios para este reconocimiento, el alcance de los derechos y su relación con los derechos humanos.

\section{LOS DERECHOS DE LA NATURALEZA}

\section{Los derechos de la naturaleza en la Constitución ecuatoriana del 2008}

La Constitución ecuatoriana del 2008, en su artículo 10, inciso segundo, determina que "La naturaleza será sujeto de aquellos derechos que le reconozca la Constitución". En el artículo 7 I se define a la naturaleza o Pachamama como el lugar "donde se reproduce y realiza la vida" y se le otorga tres derechos (artículos 7 I y $72^{8 \text { ) }}$ : I) respeto integral de su existencia; 2 ) mantenimiento y regeneración de sus ciclos vitales, estructura, funciones y procesos evolutivos; y, 3) derecho a la restauración.

7 Shelton, Dinah, Nature as a legal person, publicado en VertigO - la revueélectronique en sciences de l'environnement [En ligne], septiembre 20 I 5, disponible en http://journals.openedition.org/vertigo/l 6188.

8 Art. 7I.-La naturaleza o Pachamama, donde se reproduce y realiza la vida, tiene derecho a que se respete integralmente su existencia y el mantenimiento y regeneración de sus ciclos vitales, estructura, funciones y procesos evolutivos.

Toda persona, comunidad, pueblo o nacionalidad podrá exigir a la autoridad pública el cumplimiento de los derechos de la naturaleza. Para aplicar e interpretar estos derechos se observarán los principios establecidos en la Constitución, en lo que proceda.

El Estado incentivará a las personas naturales y jurídicas, y a los colectivos, para que protejan la naturaleza, y promoverá el respeto a todos los elementos que forman un ecosistema.

Art. 72.-La naturaleza tiene derecho a la restauración. Esta restauración será independiente de la obligación que tienen el Estado y las personas naturales o jurídicas de indemnizar a los individuos y colectivos que dependan de los sistemas naturales afectados.

En los casos de impacto ambiental grave o permanente, incluidos los ocasionados por la explotación de los recursos naturales no renovables, el Estado establecerá los mecanismos más eficaces para alcanzar la restauración, y adoptará las medidas adecuadas para eliminar o mitigar las consecuencias ambientales nocivas. 
El segundo inciso del artículo $7 \mathrm{I}$, contiene una norma de reenvío por la cual se puede aplicar, en lo posible, los principios constitucionales sobre los derechos y las reglas interpretación constitucional a los derechos de la naturaleza. Los primeros contenidos en el artículo I I y las segundas en el artículo 4279.

Algunos autores ${ }^{10}$ consideran que dos prohibiciones (i) la de apropiación de servicios ambientales" $y$, (ii) la introducción de organismos y material orgánico e inorgánico "que puedan alterar de manera definitiva el patrimonio genético nacional'2", son también derechos, opinión que considero equivocada ya que estas prohibiciones están ligadas a los derechos declarados, no son derechos en sí mismo.

9 "Las normas constitucionales se interpretarán por el tenor literal que más se ajuste a la Constitución en su integralidad. En caso de duda, se interpretarán en el sentido que más favorezca a la plena vigencia de los derechos y que mejor respete la voluntad del constituyente, y de acuerdo con los principios generales de la interpretación constitucional".

10 Algunos autores identifican de manera equivocada cuatro derechos en la Constitución ecuatoriana: derecho a la conservación integral, derecho a la restauración, precaución de extinción de especies y no introducción de organismos genéticamente modificados y no apropiación de servicios ambientales. Esto se puede leer en René Bedón "Contenido y aplicación de los derechos de la naturaleza, publicado en lusHumani, volumen 5, 2016, p. 146; y del mismo autor "Aplicación de los derechos de la naturaleza en Ecuador", publicado en la Revista Veredas de Direito, volumen 14, enero-abril 2017, pp. 21 y 22. La equivocación es creer que una prohibición es un derecho. De la lectura del artículo constitucional se puede colegir que la precaución de extinción de las especies y la no introducción de organismos genéticamente modificados son condiciones para la conservación integral de la naturaleza; en tanto que la prohibición de apropiación de servicios ambientales permite mantener esto servicios como bien público.

"Servicios ambientales son "beneficios que las poblaciones humanas obtienen directa e indirectamente de las funciones de la biodiversidad (ecosistemas, especies y genes), especialmente ecosistemas y bosques nativos y de plantaciones forestales y agroforestales. Los servicios ambientales se caracterizan porque no se gastan ni transforman en el proceso, pero generan utilidad al consumidor de tales servicios; y, se diferencian de los bienes ambientales, por cuanto estos últimos son recursos tangibles que son utilizados por el ser humano como insumo de la producción o en el consumo final, y que se gastan o transforman en el proceso". Texto Unificado Legislación Secundaria, Medio Ambiente, Libro VI. Decreto Ejecutivo 3516 Registro Oficial Suplemento 2 de 3 I -mar-. 2003.

12 Art. 73.-El Estado aplicará medidas de precaución y restricción para las actividades que puedan conducir a la extinción de especies, la destrucción de ecosistemas o la alteración permanente de los ciclos naturales.

Se prohíbe la introducción de organismos y material orgánico e inorgánico que puedan alterar de manera definitiva el patrimonio genético nacional.

Art. 74.-Las personas, comunidades, pueblos y nacionalidades tendrán derecho a beneficiarse del ambiente y de las riquezas naturales que les permitan el buen vivir.

Los servicios ambientales no serán susceptibles de apropiación; su producción, prestación, uso y aprovechamiento serán regulados por el Estado. 
Para la interpretación y aplicación de estos derechos se fijan como criterios específicos los principios de precaución y restricción, que se definen como "medidas" para limitar actividades que puedan conducir a la extinción de especies, la destrucción de ecosistemas o la alteración permanente de los ciclos naturales.

Se reconoce el derecho de los seres humanos -actuando de forma individual o colectiva- a beneficiarse del ambiente y de las riquezas naturales que les permitan el buen vivir. Se considera un deber de los ecuatorianos y ecuatorianas "Respetar los derechos de la naturaleza, preservar un ambiente sano y utilizar los recursos naturales de modo racional, sustentable y sostenible" (artículo 83.6).

Las normas citadas se complementan con el principio in dubio pro natura, para la aplicación e disposiciones legales en materia ambiental que , en caso de duda, se hará siempre en el sentido más favorable a la protección de la naturaleza. Este principio hermenéutico está contenido en el artículo 395.4, norma que contiene los principios constitucionales en materia ambiental'3.

Se pueden identificar otras 19 disposiciones constitucionales que se refieren a la naturaleza, pero no en todos los casos esta es considerada como un sujeto de derechos, el enfoque es medioambientalista. En el art. 66.22 se considera un derecho de las personas el vivir en un ambiente sano, ecológicamente equilibrado, libre de contaminación y en armonía con la naturaleza; estas pueden beneficiarse del ambiente y de las riquezas naturales que les permitan un buen vivir, que para alcanzarlo, reza el inciso tercero del artículo 275, es necesario que personas, comunidades, pueblos y nacionalidades gocen efectivamente de sus derechos, y ejerzan responsabilidades en el marco de la interculturalidad, del respeto a sus diversidades, y de la convivencia armónica con la naturaleza.

Uno de los objetivos del régimen de desarrollo (artículo 276.4) es "Recuperar y conservar la naturaleza y mantener un ambiente sano y sustentable que garantice a las personas y colectividades el acceso equitativo, permanente y de calidad al agua, aire y suelo, y a los beneficios de los recursos del subsuelo y del patrimonio natural. En el artículo 283 se determina que el sistema económico y la política económica

13 “I. El Estado garantizará un modelo sustentable de desarrollo, ambientalmente equilibrado y respetuoso de la diversidad cultural, que conserve la biodiversidad y la capacidad de regeneración natural de los ecosistemas, y asegure la satisfacción de las necesidades de las generaciones presentes y futuras.

2. Las políticas de gestión ambiental se aplicarán de manera transversal y serán de obligatorio cumplimiento por parte del Estado en todos sus niveles y por todas las personas naturales o jurídicas en el territorio nacional.

3. El Estado garantizará la participación activa y permanente de las personas, comunidades, pueblos y nacionalidades afectadas, en la planificación, ejecución y control de toda actividad que genere impactos ambientales.

4. En caso de duda sobre el alcance de las disposiciones legales en materia ambiental, éstas se aplicarán en el sentido más favorable a la protección de la naturaleza." 
"reconoce al ser humano como sujeto y fin" y "debe propender a una relación dinámica y equilibrada entre sociedad, Estado y mercado, en armonía con la naturaleza", garantizando la producción y reproducción de las condiciones materiales e inmateriales que posibiliten el buen vivir.

En las normas que regulan el "Régimen del Buen Vivir" aparece la naturaleza como parte del "marco" en el que tiene que actuar el "sistema nacional de ciencia y tecnología, innovación y saberes ancestrales", de forma específica se dice que debe respetarse "al ambiente, la naturaleza, la vida, las culturas y la soberanía" (artículo 385). Al garantizar la libertad de creación e investigación, el Estado (artículo 387.4) debe hacerlo en el marco de "la ética, la naturaleza, el ambiente, y el rescate de los conocimientos ancestrales".

Al referirse a la "gestión del riesgo" (artículo 389) se considera que es obligación estatal proteger a las personas y a la naturaleza frente de los efectos negativos de los desastres de origen natural o antrópico mediante la prevención ante el riesgo, la mitigación de desastres, la recuperación y mejoramiento de las condiciones sociales, económicas y ambientales, con el objetivo de minimizar la condición de vulnerabilidad.

Las políticas económicas deben respetar los límites "biofísicos" de la naturaleza (numerales 4 y 7 del artículo 277); en tanto que el "Régimen de Desarrollo" debe buscar el buen vivir para "Garantizar los derechos de las personas, las colectividades y la naturaleza" (artículo 277. I). Un límite para el endeudamiento público (artículo 290.2) es la "soberanía, los derechos, el buen vivir y la preservación de la naturaleza". De igual forma en las reglas referidas a la política comercial el Estado debe "desincentivar" las importaciones que "afecten negativamente a la producción nacional, a la población y a la naturaleza" (artículo 277. I). Una regla parecida se puede encontrar en el inciso segundo del artículo 319 , que plantea como objetivo que la producción el Estado debe desincentivar todas las formas de producción que atenten contra los derechos de la población o los de la naturaleza". Se declara al agua patrimonio nacional estratégico de uso público, dominio inalienable e imprescriptible del Estado, al ser un elemento vital "para la naturaleza y para la existencia de los seres humanos..." (artículo 3 | 8).

En las disposiciones que regulan la protección de la biodiversidad y recursos naturales, algunas ya citadas previamente, se determina la prohibición de suscripción de convenios o acuerdos de cooperación que incluyan cláusulas que menoscaben la conservación y el manejo sustentable de la biodiversidad, la salud humana y los derechos colectivos y de la naturaleza (artículo 403). El artículo 408, que se refiere a la propiedad estatal sobre los recursos naturales no renovables establece, entre varias condiciones para la explotación de esos recursos, el "estricto cumplimiento de los principios ambientales establecidos en la Constitución", y se determina como un deber estatal garantizar que los mecanismos de producción, consumo y uso de los recursos naturales y la energía preserven y recuperen los ciclos naturales.

La ambivalencia en el tratamiento constitucional a la naturaleza, por un lado se la trata como sujeto de derechos y por otro como un objeto de apropiación y explota- 
ción, es explicada por los defensores de personificación de la naturaleza distinguiendo el aprovechamiento dirigido a la satisfacción de necesidades vitales (un uso legítimo dirigido a asegurar la sobrevivencia) y la "crueldad por simple comodidad y el abuso superfluo o innecesario ${ }^{14 "}$. Se dice que es una doble vertiente de la protección al ambiente y que en realidad refuerza la protección jurídica, de hecho se afirma que " Sería un error pensar que los Derechos de la Naturaleza solamente se refieren a los enumerados como artículos $7 \mathrm{I}$ al 74 de la Constitución ecuatoriana. Los Derechos de la Naturaleza deben ser leídos de cara a las obligaciones que se imponen a lo largo de toda la Constitución, destacando que no se pueden confundir con los derechos ambientales, también abordados y ampliados en dicha carta magna ${ }^{15}$ ". Una afirmación contradictoria ya que, como expresamente se dice en la Constitución, los derechos que se reconocen a la naturaleza están en los artículos 7I a 74, las normas restantes tienen un enfoque medioambiental y el reconocimiento, como se explicó antes se hace en función de los derechos de las personas.

Los derechos medioambientales tienen independencia absoluta de los derechos de la naturaleza, en tanto se han construido al margen de la personificación de esta, se han aprobado para garantizar los derechos humanos y se aplican en forma autónoma a esos derechos. En otras palabras, todas las reglas constitucionales de protección al medio ambiente, los referidos a los derechos territoriales de los pueblos ancestrales, los que regulan las reservas naturales y la consulta previa, tiene un valor $y$ existencia independiente de la condición jurídica que se asigne a la naturaleza.

\section{El origen de la propuesta}

No es posible identificar en Ecuador referencias significativas a los derechos de la naturaleza de forma previa a la Asamblea Constituyente. Está propuesta era marginal inclusive en el movimiento ecologista y estaba ausente de la agenda del movimiento indígena, por ellono he podido encontrar referencia alguna en el discurso del movimiento indígena que usó, desde mediados de la década de los sesenta del siglo $X X$, el lenguaje de los derechos como un eje central de sus reivindicaciones, particularmente en lo referido al derecho al territorio ${ }^{16}$.

El movimiento indígena siempre resaltó la relación de los pueblos indígenas con

14 Zaffaroni, Raúl, "La Naturaleza con Derechos. De la filosofía a la política" de Ediciones Abya-Yala, Quito, 201 I, p. 82.

15 Martínez, Esperanza y Acosta, Alberto, Los Derechos de la Naturaleza como puerta de entrada a otro mundo posible, publicado en la Revista Direito\& Praxis, Rio de Janeiro, Vol. 08, N. 4, 2017, p. 2927-296।. Disponible en línea en http://www.scielo.br/pdf/rdp/v8n4/ 2179-8966-rdp-8-4-2927.pdf .

16 CONAIE, Las nacionalidades indígenas del Ecuador: nuestro proceso organizativo, 1992. Disponible en http://www.fes-ecuador.org/fileadmin/user_upload/pdf/0 I 2 1\%20NACIND1986_0121.pdf. 
la naturaleza, una relación descrita como "unión indisoluble", considerando a ciertos elementos de esta como sus dioses (la Tierra, la Luna, el Sol), reivindicando la importancia de sus prácticas de protección ambiental que consideraban podían ser usadas como un freno a la degradación ambiental ${ }^{17}$. Esta personificación de la naturaleza -o de sus elementos- no se asociaba al otorgamiento de derechos.

La iniciativa de otorgarle derechos de la naturaleza provino de fuera del país, no estaba en la agenda de ninguno de los actores políticos nacionales o del movimiento indígena, incluso es posible identificar cierta oposición inicial del movimiento indígena por considerar que esto podía ser una amenaza a susderechos territoriales ${ }^{18}$.

Varios autores sostienen que el otorgamiento de derechos a la naturaleza es resultado del reconocimiento de la cosmovisión indígena sobre la "pachamama" que marca una ruptura con el pensamiento eurocentrista (una forma de "descolonización" intelectual) que deja de lado el "señorío del hombre con la naturaleza'9". Quienes defienden esta idea asociación la personificación de la naturaleza como sustento para considerarla un sujeto de derechos.

Una segunda postura señala que este reconocimiento constitucional es producto de la "confluencia" de una serie de factores internos y externos, según esta explicación la iniciativa existía ya en el país y el apoyo internacional sirvió para mejorar los textos legales y contribuyó al debate en la Asamblea Constituyente ${ }^{20}$.

La tercera explicación, plenamente documentada, identifica a una organización con sede en los Estados Unidos, la CommunityEnvironmental Legal DefenseFund (CE$\mathrm{LDF}^{21}$ ), como la responsable de la iniciativa, es claro que luego de la visita de los representantes de dicha organización al Presidente de la Asamblea Constituyente, Alberto Acosta, que el tema toma un lugar en el debate constituyente. De acuerdo al CELDF la redacción de una propuesta que sirvió de base para el texto aprobado posteriormente ${ }^{22}$, fue pedida por Acosta a la organización y posteriormente se desar-

17 Ibíd.

18 Sternäng, Märta, A power analysis of the Rights of nature in Ecuador, tesis de maestría, Stockholm Resilience Centre, Stockholm University, 2018.

19 Molina-Roa, Javier, La irrupción del biocentrismo jurídico. Los derechos de la naturaleza en América Latina y sus desafíos, publicado en la Revista Ambiente y Sostenibilidad, 20 I 6, p. 65.

20 El proceso de incorporación de los derechos de la naturaleza en la Constitución del Ecuador se encuentra detallado en varios documentos, en algunos se minimiza el papel del Fondo Comunitario de Defensa Legal Ambiental (CELDF), presentándolo como un apoyo en el proceso de redacción de los textos y en la discusión, este es el caso del artículo de MihneaTanasescu, Therights of nature in Ecuador: themaking of an idea, publicado en la revista International Journal of EnvironmentalStudies, volumen 70, 2013, número 6.

21 http://www.celdf.org

22 Burdon, Peter, Rights of Nature: reconsidered, University of Adelaida, Law School, Reasearch Paper No. 201 I-0 I0, 20 I I, p. 74. Disponible en https://papers.ssrn.com/sol3/papers. cfm?abstract_id $=1709015$. 
rolló una amplia campaña de apoyo a la iniciativa ${ }^{23}$, que terminó con la incorporación de esos textos en el proyecto de Constitución.

Tampoco en la literatura jurídica nacional ${ }^{24}$ se puede encontrar una presencia importante de la asignación de derechos a la naturaleza, apenas en la primera mitad de la década de los noventa del siglo pasado esta propuesta aparece de forma marginal en los trabajos de Vladimir Serrano y como como resultado de la influencia del jurista suizo alemán, radicado en Chile, Godofredo Stutzin y su tesis de la doble personalidad del derecho ambiental ${ }^{25}$. Para Stutzinla protección medioambiental tiene dos dimensiones: la dirigida a las personas porque la alteración de las condiciones ambientales, producidas por la actividad humana pone en riesgo a sus derechos y bienes; la segunda dimensión, es la protección de la naturaleza por su propio valor, por considerar que es un fin en sí mismo y no un simple medio de bienestar humano ${ }^{26}$.

23 Sternäng, Märta, A power analysis of the Rights of nature in Ecuador, tesis de maestría, 20। 8 , Universidad: Stockholm Resilience Centre, Stockholm University.

${ }^{24}$ Es sintomático que Eduardo Gudynas, uno de los más importantes defensores y teóricos actuales de los derechos de la naturaleza, en un artículo de 1992 (Gudynas, Los múltiples verdes del ambientalismo latinoamericano) en el que pasa revista a las diferentes expresiones del movimiento ambientalista latinoamericano, no haga referencia alguna al tema derechos de la naturaleza, considerando que a este momento se había discutido ampliamente la propuesta de Stone sobre el tema.

25 Serrano P., Vladimir, Hacía la formulación de un derecho ecológico, publicado en Derecho, ecología y sociedad, compilado por Vladimir Serrano, CEDECO, Quito, 1994, pp. I I0- 166. 26 "[E]l llamado derecho ambiental o derecho del entorno sufre de un problema de doble personalidad que constituye la causa inconsciente de muchas de sus dificultades de expresión y aplicación. Las dos almas que conviven en su pecho -para hablar con Goetheproceden de dos raíces diferentes se manifiestan en dos caras distintas. Tomar conciencia de esta situación y analizarla debidamente aparece como una tarea necesaria para permitir a esta nueva rama del derecho una mejor identificación y un desarrollo más certero, liberándola de complejos e inhibiciones que son consecuencia de su conflicto interno no reconocido ni resuelto. [...] Una de las facetas del derecho ambiental se refiere al medio ambiente humano propiamente tal. Su raíz se encuentra en el reconocimiento de los daños y riesgos que afectan a las personas debido a la alteración de las condiciones ambientales producidas por las actividades de la sociedad contemporánea. Su finalidad consiste en proteger a las personas contra este nuevo tipo de violaciones en sus derechos de personalidad y propiedad, haciendo extensivas las reglas tradicionales del derecho civil y penal a las relaciones que se forman entre ellas, por ser causantes y víctimas, respectivamente, de aquellos daños y riesgos ambientales[...]. La otra cara del derecho ambiental mira también hacia el mundo de la naturaleza, pero ya no en su directa relación con el hombre, en su aspecto medio humano, sino comprendiéndolo en su totalidad, sin excluir ninguno de sus componentes, por ajenos que sean a la vida humana. No se trata ya, propiamente hablando, de un derecho ambiental, sino de un derecho ecológico o derecho de la Naturaleza" (Stutzin, 1986, pág. 37). 
A esta última dimensión la llamó Derecho Ecológico o Derecho de la Naturaleza ${ }^{27}$, que de acuerdo a la formulación original tendría como objeto la protección de la naturaleza con independencia de los intereses humanos, intereses que con frecuencia se encuentran en contradicción con los de la naturaleza debido a que la protección de la biosfera está sujeta a la prioridad que se asigna a la humanidad y por ello esta queda supeditada a las medidas que se toman a favor de la tecnosfera. Para Stutzin la única forma de superar esta dicotomía era modificando el estatus jurídico de la naturaleza, dotándole de derechos para que sea posible litigar en su defensa, al margen de los intereses humanos ${ }^{28}$.

No es una coincidencia que dos años antes de la propuesta de Stutzin, en 1972, el jurista norteamericano Christopher D. Stone publicó un ensayo ${ }^{29}$ justificando la necesidad de conceder derechos a la naturaleza ${ }^{30}$ para que existe una forma de comparecer a juicio en nombre de la naturaleza. El artículo de Stone fueescrito por el rechazo del tribunal a la demanda presentada por el Sierra Club ${ }^{31}$ que tenía por objetivo evitar la construcción de una estación invernal de esquí que afectaba a un bosque de secuoyas gigantes. El centro de la alegación de Stone estaba que el derecho a lo largo del tiempo había extendido la condición de titulares de derechos a quienes inicialmente se les había negado esta condición (niños, mujeres, negros, etc.) y que se les

27 Su propuesta "La Naturaleza de los Derechos y los Derechos de la Naturaleza" se presenta inicialmente en el año 1973, una nueva versión en 1974 y una tercera versión en 1978 como lo describe el propio Stutzin en su artículo "Un imperativo ecológico: reconocer los derechos de la naturaleza" disponible en https://www.u-cursos.cl/ciencias/20 I0/2/BA425/I/ material_docente/previsualizar?id material $=567048$

28 Stutzin, Godofredo, La doble personalidad del derecho ambiental, Ambiente y Recursos Naturales". Revista de derecho, política y administración, 1986, p. 37.

29 Stone, Christopher, Should Trees Have Standing?-Towards Legal Rights for Natural Objects, Southern California Law Review, 1972, pp. 450-501.

30 Un análisis profundo artículo de Stone y del caso se puede encontrar en: Peter Burdon, Rights of Nature: reconsidered, públicado en University of AdelaideLawSchool, ResearchPaper No. 20 I I-0 I0. https://papers.ssrn.com/sol3/papers.cfm?abstract_id=17090 I 5 .

31 Es el Sierra Club, una asociación de defensa medioambiental, la que presentó una demanda para tratar de impedir que la empresa Walt Disney construyera una estación de deportes de invierno en Mineral King Valley, un lugar en el que se encontraban arboles de Secuoya gigantes. La demanda fue rechazada por considerar que los demandantes no podía demostrar que habían sufrido una afectación directa a sus derechos. El caso conocido como Mineral King Club v. Morton dos jueces (Blackmum y Brennan) que votaron rechazar el caso mantuvieron la posición de que se requiere un interés directo para litigar, en tanto que un juez (Douglas) votó a favor de recibir la demanda razonando que "thecriticalquestion of 'standing' would be simplified and alsoputneatly in focusifwe ... allowedenvironmentalissues to be litigated ... in thename of theinanimateobjectabout to be despoiled, defaced, orinvaded". Es decir que se litigue en nombre de un objeto inanimado, siendo el tema central la capacidad de comparecer a juicio en el debate de Stone y en la posición del juez Douglas. 
reconocía esa calidad incluso a las compañías. El objetivo de Stone no era equiparar a la naturaleza con los seres humanos como sujetos morales, básicamente alegaba que era necesario otorgar a la naturaleza locus standi autónomo, es decir la posibilidad de demandar por la protección de sus derechos en forma parecida a como se demanda la protección de los derechos para un niño que no puede acudir directamente a la justicia, por medio de su representante (un curador o representante ad litem ${ }^{32}$ ).

Stone sustentaba su posición en la evolución experimentada por el derecho de propiedad, en su convicción de que es un derecho que cambia al igual que lo hace la cultura humana, con el tiempo se han ido modificando las "cosas" que pueden poseerse, quienes pueden tener propiedad y que significa tener propiedad, a partir de ello la pregunta central de Stone estaba dirigida a los cambios que se producirían en la noción de propiedad y en la cultura en caso de que se concedieran derechos a la naturaleza ${ }^{33}$. Como se puede concluir Stutzin estaba influenciado por este discurso y el objetivo era dotarle de locus standi a la naturaleza con independencia de los intereses humanos, algo que en derecho ambiental posteriormente lo hizo sin necesidad de reconocer derechos a la naturaleza.

Los defensores de los derechos de la naturaleza, en Ecuador, han encontrado una explicación a la inexistencia de una reivindicación previa en este sentido por parte de los pueblos indígenas, afirman que la lucha ecológica, en nombre de la pachamama, de los pueblos indígenas implicaba necesariamente pensar en una naturaleza sujeto de derechos ${ }^{34}$, llegando incluso a darle un alcance que no tienen trabajos previos sobre el tema. Como ejemplo se puede citar el uso que dan Esperanza Martínez y Alberto Acosta a un artículo del año 1992 del biólogo mexicano Víctor Toledo ${ }^{35}$. Afirman Martínez y Acosta ${ }^{36}$ que este autor consideraba como una tercera fase de la lucha indígena el reconocimiento de la naturaleza como "sujeto de derechos", cuando en realidad Toledo señala que la dimensión ecológica de la lucha campesina-indígena puede servirse de "La cosmovisión indígena, por ejemplo, basada en

32 En el lenguaje del derecho procesal se suele diferenciar en la representación ad agendum que sería el poder que otorga una parte a un procurador para que este actúe procesalmente cuando sea requerido, en tanto que la representación ad litem es el que actúa en un proceso específico.

33 Burdon, Peter, Rights of Nature: reconsidered, Rights of Nature: reconsidered, 20 I I, publicadoenhttps://papers.ssrn.com/sol3/papers.cfm?abstract_id=17090 I 5, p. 69.

34 Ver Martínez, Esperanza y Acosta, Alberto, Los Derechos de la Naturaleza como puerta de entrada a otro mundo posible, publicado en la Revista Direito\& Praxis, Rio de Janeiro, Vol. 08, N. 4, 2017, p. 2927-2961. Disponible en línea en http://www.scielo.br/pdf/rdp/v8n4/ 2179-8966-rdp-8-4-2927.pdf .

35 Para una referencia del trabajo de Víctor Toledo se puede revisar el siguiente artículo http:// asociacionetnobiologica.org.mx/aem/revista-volumen-9-numero- I-resumen-05 .

36 Martínez, Esperanza y Acosta,Alberto, Los Derechos de la Naturaleza como puerta de entrada a otro mundo posible, publicado en la Revista Direito\& Praxis, Rio de Janeiro, Vol. 08, N. 4, 2017, p. 2927-296। 
una percepción religiosa de la naturaleza encaja vis à vis con la necesidad de realizar una apropiación ecológicamente correcta de los recursos naturales", que implica un reconocimiento de la relación de "la naturaleza, la producción y la cultura", en la que la naturaleza puede ser considerada "objeto y sujeto de la lucha política"; dotando a las luchas locales, al asumir un elemento ecológico, "una batalla global por la defensa de los recursos naturales y la especie: utopía y naturaleza ${ }^{37 " .}$

El movimiento indígena asume posteriormente el discurso de los derechos de la naturaleza, identificó el poder del lenguaje de los derechos de la naturaleza para sus demandas políticas pero es una impostura intelectual pretender que asignarle a los derechos de la naturaleza un origen en la cosmovisión indígena y sus reivindicaciones ${ }^{38}$.

La reivindicación política aparece asociada al Sumak Kawsay "por grupos con un enfoque más bien étnico que lo utilizan para mover el discurso del movimiento indígena más hacia esta perspectiva ${ }^{39 "}$. Esto se considera una evolución de las exigencias de autonomía y autodeterminación que aparecen en la década de los setenta del siglo pasado donde el Sumak Kawsay (como forma de convivencia en armonía con la naturaleza) es reivindicado; es el pueblo Sarayaku que "denuncia la explotación de recursos naturales en su territorio como agresión contra el Buen Vivir, el "Sumak Kawsay, la vida en plenitud ${ }^{40 "}$.

José Sánchez-Parga sostiene que quienes defienden este encuentro entre la visión occidental de los derechos y la cosmovisión indígena sobre la Pachamama y el Sumak Kawsay pretenden imponer a todo la sociedad un pasado animista y mágico "... de las relaciones entre sociedades humanas y naturaleza; cuando los hombres consideraban a la Naturaleza como una realidad viva, parte de su propia naturaleza humana, y con que mantenían no sólo intercambios y reciprocidades, sino también mutuos reconocimientos e identificaciones. Y por eso también la antropomorfización de la naturaleza era complementaria a la naturalización de los seres humanos, que viven su cultura no como una 'segunda' sino como una 'primera naturaleza'4l". Esta idea de la naturaleza entran en conflicto abierto con la pluralidad valorativa de una sociedad democrática. El

37 Toledo, Víctor, Utopía y Naturaleza. El nuevo movimiento ecológico de los campesinos e indígenas de América Latina, publicado en la Revista Nueva Sociedad, noviembre-diciembre 1992, pp. 75-82.

38 Zaffaroni, Raúl, "La Naturaleza con Derechos. De la filosofía a la política" de Ediciones Abya-Yala, Quito, 201 I, pág. 103-117.

39 Altmann, Philipp, El movimiento indígena ecuatoriano y su discurso - Un análisis de discurso centrado en los conceptos, conferencia presentada en el marco de la I6th International ConferenceontheH History of Concepts, Bilbao y San Millán de la Cogolla (La Rioja), 29 a 3 I de agosto del 20 I3. Disponible en https://www.academia.edu/49/2862/EI_movimiento_ind\%C3\%ADgena ecuatoriano_y_su_discurso_-_Un_an\%C3\%Al lisis_de_discurso_centrado_en_los_conceptos .

40 Ob. Cit., p. 60.

41 Sánchez-Parga, José, Alternativas virtuales vs. cambios reales, CAAP, Quito, 2014, pp. 103 
"pachamamismo", para usar otra noción de José Sánchez Parga, significaría “ . . un reconocimiento personal de la naturaleza o su personalización, se incurre en una 'desnaturalización' de la misma naturaleza, cuando se la fetichiza en un mundo post-animista... $[E] l$ animismo primitivo, más que una creencia religiosa respondía a una experiencia de sociedades, que vivían en personal relación con la naturaleza, en un sistema de intercambios mágicos y rituales, que regulaban todas sus relaciones con ella ${ }^{42 "}$.

\section{Los fundamentos para otorgarle derechos a la naturaleza}

No existe un acuerdo sobre el fundamento para otorgarle derechos a la naturaleza, existen consideraciones (i) utilitarias, pensadas en cómo puede mejorarse la protección medioambiental, siendo esta protección una medio para garantizar los derechos de los seres humanos en el presente y para las futuras generaciones; (ii) otros parten de la idea de que la naturaleza tiene un valor intrínseco; (iv) para algunos este reconocimiento deriva de una consideración animista al ver a la naturaleza como un ser vivo o un ser superior; $y$, (iv) algunos consideran que el fundamento es de carácter político, la necesidad de enfrentar al modelo económico dominante, declarar a la naturaleza como sujeto de derechos se considera un freno a "un capitalismo desmedido que estima que todo objeto es un bien apropiable al considerarlo como una mercancía ${ }^{43 "}$.

Estas propuesta de líneas justificatorias se identificaron a partir de las elaboraciones teóricas paralelas, o posteriores. a la aprobación del texto constitucional ecuatoriano, ya que en el Ecuador no existen debates previos al proceso constituyente sobre este tema, si endo posible identificar cuatro líneas de justificación ${ }^{44}$.

\section{La justificación utilitarista}

La perspectiva "utilitarista" agrupa a todas las justificaciones que sostienen qye transformar a la naturaleza en sujeto de derechos permitiría una mejor y mayor protección del ambiente y contribuiría a un desarrollo sostenible "...que no amenace la existencia de los ecosistemas, garantizando, así que las futuras generaciones puedan disfrutar, de la misma manera que nosotros, de la naturaleza y sus beneficios ${ }^{45}$.

Elizalde Hevia lo expresa de forma clara

42 Ob. Cit., p. 113.

43 Simon C., Farith, "Derechos de la naturaleza: ¿innovación trascendental, retórica jurídica o proyecto político?, publicado en Revista luris Dictio delColegio de Jurisprudencia Universidad San Francisco de Quito, Volumen I5, enero 2013, p. 9-38.

44 Ibíd.

45 Linzey, Thomas Alan, Aportes sobre los Derechos de la Naturaleza, publicado en Derechos de la Naturaleza, Acosta, Alberto y Martínez, Esperanza (compiladores), Abya-Yala, Quito, 2009, pp. 109-1 10. 
...asumiendo que es imprescindible la protección de la naturaleza, sería necesario preguntarse cómo hace más eficaces las leyes que eventualmente se expedirían para protegerla frente a las agresiones y la depredación que constantemente sufre. Si existe conciencia de que debe ser utilizada con prudencia y no abusar de ella. Si se considera que es un absurdo pensar que el ser humano es propietario de la naturaleza. Es decir si en realidad, la naturaleza ha dejado de ser objeto propiamente dicho y se le comienzan a reconocer intereses distintos a los humanos ${ }^{46}$.

La justificación utilitarista busca "elevar" el nivel de protección jurídica de la naturaleza, asumiendo que las leyes ambientales son insuficientes y que se han revelado ineficientes para detener la destrucción del medio ambiente y preservarlo para futuras generaciones.

El Informe de mayoría sobre los Derechos de la Naturaleza de la Asamblea Nacional Constituyente, presentado en la Asamblea Nacional Constituyente podría considerarse como el mejor ejemplo de las argumentaciones puestas al servicio de un fin pragmático

Lo que nos preocupa y lleva a proteger a la Naturaleza, elevándola de objeto de protección jurídica a sujeto de derecho, es la necesidad de cambiar el paradigma de desarrollo, el enfoque de aproximación legal y la relación que el ser humano tiene con su entorno, a fin de evitar o, al menos paliar las imprevisibles consecuencias que se producirán si mantenemos el sistema de depredación antropocéntrico ${ }^{47}$ (resaltado no consta en el original).

Esta perspectiva también es la asumida por Néstor Cafferatta ${ }^{48}$

Aunque no se diga, se trata a la sociedad como un ente moral, uniforme, homogéneo, y un centro de prerrogativas propias, titular de acciones y derechos inherentes. Asimismo, la naturaleza se constituye en un sujeto de derecho, digno de protección. No ya tan sólo en objeto de defensa. Todo ello en aras de la preservación del medio ambiente, la calidad

\footnotetext{
46 Elizalde Hevia, Antonio, Aportes sobre los Derechos de la Naturaleza, publicado en Derechos de la Naturaleza, Acosta, Alberto y Martínez, Esperanza (compiladores), Abya-Yala, Quito, 2009, pp. 70-7I.

47 Asamblea Constituyente del Ecuador, Informe de Mayoría sobre los Derechos de la Naturaleza, Mesa No. I de Derechos Fundamentales y Garantías Constitucionales, 2008. P. 4.

${ }^{48}$ Cafferatta, Néstor y Morello, Augusto, La Sociedad y la Naturaleza como Sujetos de Derecho, Revista el Derecho, Número monográfico, Tomo 212, p. 899. 
de vida y el desarrollo sustentable. Este parece ser la nueva modalidad de los tiempos que vivimos.

El nuevo estatus jurídico de la naturaleza no tiene por objeto la protección de un bien valioso en sí mismo, sino evitar las "imprevisibles consecuencias" de la destrucción ambiental.

\section{LA JUSTIFICACIÓN DEL VALOR INTRÍNSECO O ESENCIALISTA}

Se sustenta en la idea básica, aunque pueda asumir diferentes manifestaciones, que "Cuando se reconocen los derechos de la Naturaleza, se están admitiendo valores propios o intrínsecos en ella49".

Se parte del supuesto que la atribución de un derecho está ligado a una "esencia", esto podría darse a partir de tres "abordajes", dice Gudynas ${ }^{50}$, que se presentan confundidos y superpuestos en los postulados de la llamada "ecología profunda": I) el bienestar y florecimiento de la vida humana y no humana tiene un valor en sí mismo, de forma independiente a la utilidad que presten a los humanos ${ }^{51}$; 2) el reconocimiento de que un objeto es valioso en cuanto posee propiedades que no dependen de las relaciones con el entorno u otros objetos; $y, 3$ ) las cosas tienen un valor "objetivo" que no depende de las evaluaciones que le otorguen terceros ${ }^{52}$.

Se busca sustraer la calificación de un objeto, de un ser, de valoraciones externas a él, por tanto el derecho se limita a reconocer jurídicamente algo que es valioso con independencia de lo jurídico.

Quienes defienden esta posición sostienen que se produce un cambio radical desde un antropocentrismo que considera que "todas las medidas y valoraciones parten del ser humano, y los demás objetos y seres son medios para sus fines"; hacia un biocentrismo, que implicaría, en palabras de Gudynas, que la Naturaleza tiene valores

49 Gudynas, Eduardo, La Naturaleza con Derechos. De la filosofía a la política, Abya-Yala, Quito, 201 I, p. 245

50 Gudynas, Eduardo, Derechos de la naturaleza. Ética biocéntrica y políticas ambientales, Abya-Yala, Quito, 2016, p. 248-249.

51 Gudynas, Eduardo, Aportes sobre los Derechos de la Naturaleza, publicado en Derechos de la Naturaleza. El futuro es ahora, Alberto Acosta y Esperanza Martínez (compiladores), editorial Abya - Yala, Quito, 2009, pp. ; del mismo autor el artículo, ya citado, "Los derechos de la Naturaleza en serio. Respuestas y aportes desde la ecología política”, pp. 248-249; y, "La senda biocéntrica: valores intrínsecos, derechos de la naturaleza y justicia ecológica”, Op. Cit., pág. 50. 52 Estas ideas se pueden encontrar en los textos de Gudynas: "Aportes sobre los Derechos de la Naturaleza", publicado en "Derechos de la Naturaleza. El futuro es ahora", Alberto Acosta y Esperanza Martínez (compiladores), editorial Abya - Yala, Quito, 2009 ; "La senda biocéntrica: valores intrínsecos, derechos de la naturaleza y justicia ecológica”, Op. Cit., pág. 50.

Devall y Sessions, citados por Gudynas, Op. Cit., Los derechos de la Naturaleza en serio. Respuestas y aportes desde la ecología política", pág. 270. 
propios, al igual que todas las formas de vida, una igualdad que se traduce en que “... todas las especies son "iguales en sus derechos a vivir y florecer y alcanzar sus propias formas de desplegarse y auto-realizarse'"'53.

El filósofo alemán Otfried Höffe sostiene que quienes defienden, lo que él llama una "política ecológica", buscan establecer un nuevo imperativo categórico

Los representantes del debate ecológico abogan en términos tan sencillos como poco modestos por un nuevo imperativo categórico o una nueva moral, respectivamente. Bajo diferentes términos -como el carácter sagrado de la vida (Hans Jonas) o defendiendo al menos dos generaciones antes y, sin embargo, no mencionando el respeto (Albert Schweitezar) o la paz con la naturaleza (Meyer-Abich), o bien la capacidad de sufrimientose sostiene una misma idea rectora; se pretende que la moral abandone lo que antes era natural para ella: una referencia exclusiva al hombre. Si denominamos antropocéntrica aquella moral que defiende la referencia exclusiva y a la moral que rechaza la exclusividad ya sea biocéntrica, cuando se trata de cualquier vida, o patocéntrica, cuando se trata únicamente de vida capaz de sufrir, hemos encontrado el primer elemento, la piedra fundamental. Este elemento define la pregunta rectora: "moral antropocéntrica o bien biocéntrica o patocéntrica ${ }^{54}$.

Es llamativo que la idea del reconocimiento de lo "intrínseco", es de decir del ser (de lo ontológico)son las mismas ideas que sustentan las propuestas teóricas más conservadores con respecto a la categoría persona (en el mundo jurídico) y la perspectiva unitaria de ese concepto, que equipara en vida humana, ser humano y persona (como categoría jurídica), sus defensores asumen una paridad ontológica entre persona y Homo sapiens (como ser en general y sus propiedades metafísicas), es decir, la lógica que sustenta la total exclusión de cualquiera que no sea humano (actuando individual o colectivamente) como titular de derechos es la que se usa para sostener la tesis contraria ${ }^{55}$ y ampliar la protección a la naturaleza incluso extendiendo nociones como la dignidad como sustento para ese reconocimiento.

\footnotetext{
53 Ibid.

${ }^{54}$ Höffe, Otfried, Animal Morale, publicado en "El proyecto político de la modernidad", Fondo de Cultura Económica, México, 2008, p. 248.

55 A propósito de éste tema se puede consultar el trabajo de Ilva Hoyos Castañeda, "La persona y sus derechos", Temis, Bogotá, 2000, pp. I - I6. Es especialmente valiosa, con el propósito de entender la división que hace entre teoría unitaria y reduccionista y propone 10 tesis sobre el tema, la primera es la citada en este trabajo "... admitir la paridad ontológica entre el hombre y la persona, esto es, aceptar que el criterio objetivo para determinar quién es persona es su pertenencia a la especie homo sapiens" (pág. 4).
} 
Esto pasa, como lo hace Peter Singer, decuestionar al mismo concepto de dignidad humana como un "valor intrínseco de todos los hombre, como si los hombres poseyeran algún valor que los otros seres no tuvieran,, o dice que los humanos, y sólo los humanos 'son fines en sí mismos', mientras que 'toda cosa que no sea una persona sólo puede tener valor para una persona ${ }^{56 "}$.

\section{La justificación animista}

Como parte de esta visión esencialista se justifica el hecho de que la cosmovisión indígena con los conceptos sumak kawsay y la pachamama ${ }^{57}$ han sido recogidas por un nuevo constitucionalismo -el constitucionalismo andino-, esto implica que su comprensión del entorno y de sus prácticas de convivencia han roto con el discurso de la modernidad.

Sostienen que el Sumak kawsay ("buen vivir") es considerado en la cultura andina un sistema de vida que contiene una serie de principios, normas o reglas que establecen un modelo económico, social, político de sociedad ${ }^{58}$. Este "modelo" depende de cuatro principios básicos que se afirma son parte de la filosofía andina ${ }^{59}$ : relacionalidad, correspondencia, complementariedad, reciprocidad. Uno de los elementos de esa visión es la convivencia armónica con el entorno. Estermann considera que el "núcleo principal del pensamiento andino" es la relacionalidad de todo acontecer y ser: "el individuo como tal es vano y perdido, si no está bien insertado dentro de un sistema de relaciones múltiples": lo explica de la siguiente forma "El individuo concebido como ser particular y autónomo es para el pensamiento andino algo sin lugar (u-tópico), sin fundamento (an-árquico) y sin centro (ex - céntrico)"60. El "cosmos como un sistema ético" tiene como la expresión más clara la relación de los individuos con "... la pachamama, la madre tierra. Sólo cuando se respeta debidamente las relaciones entre ser humano y cosmos, la tierra produce y es fértil"'6l. El principio de correspondencia y transición entre micro y macrocosmos, que implica que el "orden cósmico y el orden humano corresponden mutuamente e interfieren de diferentes maneras" 62 .

56 Singer, Peter, Desacralizar la vida humana. Ensayo de Ética, Catedra, Madrid, 2003, p. 17.

57 Zaffaroni, Raúl, "La Naturaleza con Derechos. De la filosofía a la política" de Ediciones Abya-Yala, Quito, 2011, pág. 103-117

58 Llasag Fernández, Raúl, "Los Derechos de la Naturaleza y la Naturaleza de sus Derechos”, Ministerio de Justicia y Derechos Humanos, Quito, 201 I, pág. 82.

59 Todos los artículos que he revisado reproducen un trabajo de Josef Estermann (misionero, filósofo y teólogo suizo) "Filosofía Andina”, para explicar las particularidades de la lógica andina. Josef Estermann y Antonio Peña, "Filosofía Andina", IECTA-CISA, Cuadernos de Investigación en Cultura y Tecnología Andina No. 12, Iquique, 2004.

60 lbíd., pág. 10.

61 lbíd., pág. II.

62 lbíd., pág. 18. 
Así, la pachamama, en la racionalidad andina, se dice es

... fuente principal de vida, continuación del proceso cósmico de regeneración y transformación de la relacionalidad fundamental y del orden cósmico. En este sentido la Pachamama vive, "es un ser vivo orgánico que 'tiene sed'[...], que se 'enoja', que es 'intocable' [...] que 'da recíprocamente'[...] La naturaleza (pachamama) es un organismo vivo, y el ser humano es, en cierta medida, su criatura ${ }^{63}$.

Por ello se afirma que tiene vida, que los seres humanos somos una parte al igual que los animales, los minerales, el agua.Este discurso asume que los pueblos ancestrales saben "relacionarse" con la naturaleza, respetan sus ciclos, su forma de vida es medioambientalmente responsable; frente a los pueblos occidentales, especialmente los capitalistas, que son depredadores, irresponsables con el medio ambiente y son los causantes de los desastres ecológicos.

Hay varios estudios que desmienten la hipótesis de que "...todos los pueblos indígenas del pasado eran (y que los actuales todavía son) administradores moderados y ecológicamente prudentes de sus respectivos entornos, conocían y respetaban profundamente la naturaleza, vivían con inocencia en un virtual paraíso...." ${ }^{64}$

En realidad, ambas posiciones extremas de esta controversia - la de los racistas [que consideran que los indígenas no tienen capacidad para manejar sus recursos naturales] y la de los creyentes en los paraísos del pasado- cometen el error de considerar que los pueblos indígenas del pasado eran esencialmente diferentes de los pueblos del moderno Primer Mundo, ya sea por su inferioridad o su superioridad. Gestionar de forma sostenible recursos ambientales ha sido siempre difícil, desde los tiempos en que el Homo sapiens desarrolló el ingenio, la eficiencia y las destrezas de caza modernas desde hace aproximadamente cincuenta mil años ${ }^{65}$.

Esto no significa negar el hecho de que varios pueblos ancestrales tengan una relación "mística", respetuosa del entorno, que sepan gestionar de forma adecuada sus recursos naturales; sin embargo esto no es un atributo generalizable de acuerdo a los datos disponibles en la actualidad ${ }^{66}$.

63 Llasag Fernández, Raúl, "Los Derechos de la Naturaleza y la Naturaleza de sus Derechos", Op, Cit., pág. 85.

64 Diamond, Jared, Colapso, Debate, Bogotá, 2006, pág. 30.

65 Ibíd., pág. 31.

66 Un libro que aporta información muy interesante sobre éste tema es: |49| New revelations of theamericasbefore Columbus, escrito por Charles C. Mann, RandomHouse, New York, 2005. Es- 
Al margen de este debate varios autores relacionan -de hecho afirman- que confluyen el concepto andino de la Pachamama y las tesis occidentales sobre Gaia un "supraorganismo extremadamente complejo, que requiere de cuidados y debe ser fortalecido, es sujeto de dignidad y portador de derechos, porque todo lo que vive tiene un valor intrínseco, tenga o no uso humano."67

El uso de la "hipótesis Gaia" (ahora la "tesis Gaia") ,como base científica para sustentar la visión de la naturaleza como un sujeto con vida y por tanto con valor intrínseco, es recurrente, lo que ha permitido a sus defensores darle un valor "científico" a sus afirmaciones.

He revisado trabajos de James Lovelock (quien formuló la hipótesis Gaia) y los escritos de Lynn Margulis (una de las cientíicas evolucionistas más relevantes) para verificar las afirmaciones de los defensores de esta hipótesis.

Lynn Margulis, en su libro "Captando Genómas", al referirse a este tema lo hace de la siguiente forma

La hipótesis Gaia de James Lovelock ha representado un gran avance desde que Vernadsky reconociera a la vida como fuerza geológica. Lovelock postula que tanto la composición química de la atmosfera, como su temperatura global, la salinidad de sus océanos y la alcalinidad de la superficie de éstos ( $\mathrm{pH} 8,2)$, no son parámetros aleatorios, sino que presumiblemente vienen regulados por el metabolismo de la suma de la vida sobre la Tierra. Esa clase de modulación global no significa que la superficie de nuestro planeta sea el equivalente a un organismo, porque a diferencia de la biosfera, no pude sobrevivir de sus propios residuos ni respirar sus propias excreciones gaseosas. Sin embargo, la superficie de la Tierra sí presenta algunos rasgos propios de los organismos. Está constituida en gran medida a base de células que se reproducen, toma sus nutrientes del agua y produce incesantemente residuos. Ambas entran en asociaciones ecológicas, en ocasiones simbióticas, absolutamente necesarias para el reciclado de residuos, lo cual determina que el reino celular se expanda. El resultado consiste en que, con el paso del tiempo, el medio ambiente se vuelve cada vez más organizado, diferenciado y

pecialmente interesante es el capítulo 3 "In theLand of FourQuarters", en el que se relata el impacto que en el hombre tenía en la naturaleza antes de la llegada de los españoles (pp. 68- 106).

${ }^{67}$ Acosta. Alberto, Los Derechos de la Naturaleza. Una lectura sobre el derecho a la existencia, Abya-Yala, Quito, 20I I, pág. 345. En el mismo sentido Zaffaroni en el texto aquí citado pp. 75 a 84. 
especializado $68 "$ (resaltado no consta en el original).

En otras palabras, la Tierra actúa como un organismo pero no es un organismo. Margulis, en la misma obra, se refiere a la "hipótesis" de Lavelock de la siguiente forma

Al darle al planeta el nombre de la diosa griega, Lovelock, en un verdadero acto de bautismo, convirtió su idea en memorable, tanto para la ciencia como para sus enemigos. Logró personalizar el objeto de estudio y centrar la atención de sus colegas en sus características sobresalientes. En la mente de muchos, «Gaia» quedó reducida a un eslogan: «la Tierra es un organismo gigante», de hecho un organismo «femenino». ¿Cómo -protestábamos ante Lovelock- podría ser la Tierra un «organismo», cuando ningún organismo puede vivir de sus propios residuos? ¿Por qué insistes en promover la imagen de la Tierra como un ser único y gigantesco -le recriminábamosalejándote de la ciencia y atrayendo hacia a (sic) ti la potencial enemistad de respetables colegas? ¿Por qué no decir que Gaia es un ecosistema gigante, que reconoce la pluralidad de los seres que lo componen, le sugeríamos. Pero él insistía. El término «ecosistema» le parece engorroso, difícil de definir y completamente opaco para quienes no estén familiarizados con la ecología. Es más, se atreve a defender su metáfora de la diosa. «Si consigo que piensen en la Tierra como en un ser vivo explica- aprenderán a respetarla y a amarla. Si el planeta no es más que un montón de rocas, no hay inconveniente en darle puntapiés y maltratarlo. A nadie le importa. Por supuesto, Gaia no es un organismo único ni ninguna diosa, pero está viva y merece nuestra comprensión y nuestra reverencia ${ }^{69},{ }_{.}$

Dos breves citas de Lovelock confirman el uso inicialmente metafórico de Gaia, las dos han sido tomadas del que se considera su mejor obra "Las edades de Gaia": "Para mí era evidente que la Tierra estaba viva en el sentido de que era un sistema autorganizado y autorregulado ${ }^{70 "}$.

La homeostasis, base de la propuesta, se explica como

La hipótesis de Gaia, cuando la expusimos en los años

\footnotetext{
68 Margulis, Lynn; Sagan, Dorion, Captando genomas. Una teoría sobre el origen de las especies, Kairos, Barcelona, 2003, p. 183.

69 Ibíd.,p. $187-188$.

70 Lovelock, James, Las edades de Gaia. Una biografía de nuestro planeta vivo, Tusquets, Barcelona, 2000, p. 54 
setenta, suponía que la atmósfera, los océanos, el clima y la corteza de la Tierra se encuentran ajustados a un estado adecuado para la vida por el comportamiento de los mismos organismos vivos. Concretamente, la hipótesis de Gaia dice que la temperatura, el estado de oxidación, de acidez y algunos aspectos de las rocas y las aguas se mantienen constantes en cualquier época, y que esta homeostasis se obtiene por procesos cibernéticos llevados a cabo de manera automática e inconsciente por el biota. La energía solar sustenta estas condiciones favorables para la vida. Estas condiciones son sólo constantes a corto plazo y evolucionan en sincronía con los cambios requeridos por el biota a lo largo de su evolución. La vida y su entorno están tan íntimamente asociados que la evolución afecta a Gaia, no a los organismos o al medio ambiente por separado ${ }^{71}$ (Resaltado no consta en el original)

Lovelock ${ }^{72}$ no considera a Gaia como una entidad sintiente, pero no le molesta - de hecho expresó satisfacción- que sus ideas hayan dado paso a interpretaciones espirituales, una de ellas fue recogida por Theodore Roszak que parte de la idea de que la complejidad del mundo natural es resultado de un orden, en el que el objetivo esencial de la existencia es "despertar en nuestro interior el sentimiento de reciprocidad medioambiental que nos es connatural", él lo llama "inconsciente ecológico" que sería el elemento central de nuestro espíritu y nos permitiría asumir un sentido de trascendencia, brindando al ser humano una percepción de finalidad y plenitud que no puede encontrarse en ningún otro lugar ${ }^{73}$. Lo que Roszak propone es una forma de deísmo ${ }^{74}$, una nueva forma de religión.

Estas ideas de carácter místico se reflejan también en el biólogo evolutivo Edward Osborne Wilson quien sostiene que la amenaza más importante que enfrenta la humanidad es la pérdida de la biodiversidad, el ritmo de su destrucción es tan rápido y catastrófico que no podemos imaginar las consecuencias, pero cree que estamos frente a la sexta extinción masiva; la primera provocada por los seres humanos en 550 millones de años de evolución ${ }^{75}$. Wilson afirma que la única posibilidad de sobrevivencia es la biofilia, un término acuñado por él en 1984, una tendencia innata

7l Ibíd., p. 40.

72 Una de las consecuencias de la hipótesis Gaia es que la evolución sería resultante -fundamentalmente- de la "integración general de los organismos vivos en la red simbiótica global", en la biomasa planetaria, y no la selección natural (Watson, 20I5, pág. 657).

73 Watson, Peter, La edad de la nada, Crítica, Barcelona, 20I5, p. 655.

74 Roszak, Theodore, Where the Wastelend Ends: Politics and Trascendence in Postindustrial Society, Faber and Faber, Londres, 1973, p. 63.

75 Watson, ob. cit., p. 651. 
-sostiene Wilson- a asociarnos con todo lo vivo como un resultado de nuestra trayectoria evolutiva. Esto podría ayudar que los seres humanos encontremos en la biofiliauna forma de darle significación a nuestra existencia y encontrar un medio para lograr una realización personal,que permitiría aprovechar esta "tendencia a centrar nuestra atención en la vida y en todos aquellos procesos que se asemejan a lo biológico ${ }^{76}$ ", lo que nos llevaría a actuar con humildad frente a todas las criaturas vivas del planeta, promoviéndose una suerte de unión mística con la naturaleza que podría contribuir a frenar la destrucción de la biodiversidad ${ }^{77}$.

En otras palabras, promueve una suerte de religión basada en la biología capaz de enfrentar y reemplazar -sostiene Wilson- a la creencia más peligrosa para la sobrevivencia de la naturaleza, el cristianismo que con su idea de que el "reino no es de este mundo" abre la puerta a una explotación del entorno natural sin importar llegar hasta su consunción total a la espera de esa "segunda vida ${ }^{78 "}$.

Es claro que la biofilia solo es compatible parcialmente con la idea de los derechos de la naturaleza en la que los elementos bióticos y abióticos son igual de trascendentes, en la medida de la importancia que tiene el todo.

Mario Melo, uno de los más activos defensores del cambio constitucional, en lo que al inicio me pareció un uso metafórico de los conceptos, pero posteriormente -leyendo otros trabajos suyos parece que es una descripción de lo que cree

Que la Naturaleza es nuestra madre, es una verdad evidente que la repiten todos los niños de preescolar. Siendo nuestra madre, ella cumple día a día con su deber de ser soporte de vida para todas las especies, incluyendo la especie humana. Madre al fin, ella tolera paciente pero no indolente, cuanto agravio le causamos los humanos en nuestra desenfrenada carrera por la acumulación de capital y el desarrollo ${ }^{79}$.

Sostiene que

A la Naturaleza, como ser, no se puede mezquinar sus derechos. El derecho de la Naturaleza a existir y a que sus ciclos vitales que le permite sostener la vida no sean alterados

\footnotetext{
76 Wilson, Edward Osborne y Kellert, Stephen, The Biophilia Hypothesis, Island Press, Washington D.C., 1993, p. 23.

77 Watson, ob. cit., p. 654.

78 Ibíd.

79 Melo, Mario, Ob. Cit., "Derechos de la Naturaleza. El futuro es ahora", Abya-Yala, Quito, 2009, pág. 52.
} 
por agresiones provenientes de la especie humana... ${ }^{80}$.

Obviamente la visión animista y la esencialista se relacionan, sin embargo se pueden estudiar de forma diferenciada, en el animismo se asume que la naturaleza tiene un derecho a existir y seguir sus propios procesos vitales ${ }^{81}$ que cumple con un deber que es sustentar la vida ${ }^{82}$. Es "un 'alguien' que nos procrea, nos nutre y nos acoge" ${ }^{83}$.

La perspectiva esencialista le da un valor ontológico a la Naturaleza, un fin en sí mismo, pero no -necesariamente- se le atribuye una "vida", o considerarla un organismo vivo con un "proyecto de vida".

Estas dos posiciones son una expresión de la llamada deepecology, 'ecología profunda', 'ecología radical', 'biocentrismo' o 'econcentrismo'. En resumen, la 'ecología radical' promueve que la naturaleza sea un sujeto de derecho (pasar del objetivismo al subjetivismo), esto por considerar que tiene una dignidad propia y unos derechos que pueden ser opuestos a los hombres. Se propone pasar de una comprensión antropocéntrica (que implica el humanismo) a una lógica biocéntrica, en esta el ser humano pierde su condición de fuente de valores y el fin de estos; ya no es el centro, es parte de la evolución sin privilegio alguno en relación a los demás componentes de la naturaleza (del antropocentrismo al ecocentrismo); se promueve el paso del individualismo al holismo (no a un colectivismo o comunitarismo) que implica la integridad del todo (del individualismo al holismo). Como bien señala FrancoiseOst, a quien he seguido en esta descripción

....al superar el dualismo cartesiano entre sujeto y objeto,... se desemboca en una asimilación total de los elementos. En Descartes teníamos una dualidad sin ninguna consideración de sus relaciones e identidades, lo que generaba jerarquía y explotación aquí heredamos una unidad sin ninguna consideración de las diferencias, lo que genera confusionismo y reduccionismo ${ }^{84}$.

El ambientalismo radical asume todo lo que sirve a su posición y deja de lado toda la información científica que la contradice, este suerte de relativismo en el que no existe una única respuesta correcta e independiente de las circunstancias sociales y culturales, en ese sentido todos los hechos estarían construidos social-

80 lbíd, pág. 60.

${ }^{81}$ Gudynas, Eduardo, "Aportes sobre los Derechos de la Naturaleza", Op. Cit., pág. 49.

82 Acosta,Alberto, "Los grandes cambios requieren de esfuerzos audaces", publicado en "Derechos de la Naturaleza. El futuro es ahora", Op. Cit., pág. 17.

83 Eduardo Gudynas, Op. Cit., "Aportes sobre los Derechos de la Naturaleza”, pág. 57.

${ }^{84}$ Ost, Françoise, Naturaleza y Derecho. Para un debate ecológico, Mensajero, Bilbao, 1996, p. 148. 
mente, esto lleva a la idea de que los hechos del mundo natural pueden ser ciertos en una cultura y falsos en otro. El problema central es la confusión de hechos con valores, valores con creencias y el mundo con nuestro conocimiento de él. Al final la verdad sería una creencia compartida y por tanto separada de los hechos, confundiéndose además los contextos de descubrimiento con los de justificación. En otras palabras quienes promueven los derechos de la naturaleza provenientes del deepecology defienden su posición confundiendo lo que quisieran que la ciencia diga con lo que la ciencia dice en realidad. De alguna manera se convierten en anarquistas ingenuos, porque parten de una observación correcta y llegan a una conclusión totalmente falsa ${ }^{85}$.

Así ". . . los ecorradicales no sólo quieren dar al 'significado trascendental' forma de naturaleza, sino que proponen, literalmente idolatrarlo.[...] Dejando de lado el pastiche, la superficialidad y el fresco escepticismo de los eruditos avantgarde, muchos ecorradicales persiguen la reafirmación de unos valores religiosos o casi religiosos, fundamentados en un ecología espiritualizada ${ }^{86}$. Por ello "... propagan la idea de que la ciencia no es más fidedigna que el chamanismo y, sobre todo, arguyendo que la propia razón es la fuente última de la crisis ambiental, los filósofos verdes hacen bien poco por enriquecer la capacidad de la gente para pensar acerca del mundo y sus problemas reales. La adoración del espíritu de la Tierra puede ser beneficiosa psicológicamente para ciertos individuos pero en el plano social es síntoma de una tendencia peligrosa a la evasión ${ }^{87 "}$.

\section{La justificación política}

Reconocer a la Naturaleza como un sujeto derechos y promover el buen vivir, se dice es cuestionar "el modelo neoliberal en relación a la organización de la economía y de la sociedad, pero en última instancia el mismo sistema capitalista"88. La Naturaleza objeto "ha convertido a todos los seres vivientes en materia prima de diferentes procesos industriales" 89 .

Se considera que el reconocimiento de la Naturaleza como sujetode derechos se convierte en una tarea "civilizatoria" que implica su "desmercantilización", para ello "Los objetivos económicos deben estar subordinados a las leyes del funcionamiento de los

85 Ob. Cit., pp. 297-330.

${ }^{86}$ Lewis, Martin W., Radical environmental philosophy and the assault on rason, publicadoenThe Flight fron Science and Reason, Gross, Levitt y Lewis (editores), John Hopkins University Press, Annals New York Academy of Science, 1996, p. 219.

87 Ob. Cit. p. 220.

${ }_{88}$ Martínez, Esperanza, Prólogo del libro "La Naturaleza con derechos", Abya-Yala, Quito, pág. 12.

89 Ibíd., pág. 7. 
sistemas naturales, sin perder de vista el respeto a la dignidad humana, siempre procurando asegurar la calidad de vida de las personas." 90 . Por ello los "derechos de la naturaleza tienen un componente político: constituyen un llamado al mundo entero para iniciar un cambio urgente"91.

Esto implica, dicen los defensores de esta posición, contraponer el modelo de desarrollo capitalista basado en la explotación de los recursos naturales, en el que la naturaleza se pone al servicio del capital92, a otra en la que se reconoce a la Naturaleza como quien "nos procrea, nos nutre, nos acoge", en la que debe imperar una "relación de no utilización, sino de respeto e incluso de solidaridad"93.

No se niega la posibilidad de que los seres humanos satisfagan sus necesidades vitales "pues la vida es un continuo en que todos sobrevivimos, pero excluye la crueldad por simple comodidad y el abuso superfluo e innecesario"94. Se afirma, que desde la vigencia de los derechos de la naturaleza, es "indispensable avizorar una civilización postcapitalista, que exige una lucha de liberación..." 95.

Los defensores de esta posición caen en una simplificación, asocian un modelo político al respeto del medio ambiente. Existen suficientes evidencias que los niveles de deterioro y destrucción ambiental son (fueron) igualmente graves en países que optaron por un sistema político diferente al capitalismo, ejemplo de ello son la ex Unión Soviética y China. Por el contrario, Nueva Zelanda es reconocido como país con un gran respeto por la naturaleza y con altos estándares de protección medioambiental ${ }^{96}$.

Se podría usar solo parcialmente las argumentaciones que el derecho ambiental sostiene, en tanto se dirige a mejorar las condiciones de vida de las personas y se garantiza las condiciones para el ejercicio y goce de otros derechos, una posición que sería rechazada automáticamente por una buena parte del movimiento que promueve los derechos de la naturaleza ya que no consideran que esto sea solamente un medio, como explique anteriormente, sino un fin en sí mismo.

La filosofía ambiental radical o ecoradicalismo afirma que "...los seres humanos

90 Acosta, Alberto, "Los Derechos de la Naturaleza, una lectura sobre el derecho a la existencia, Abya-Yala, Quito, pág. 339.

9l Borja Ortiz, Andrés, Derechos de la naturaleza, publicado en Nuevas instituciones del Derecho constitucional ecuatoriano, Tomo I, INREDH, Quito, pág. 132.

92 Cfr. Martínez, Esperanza, Los Derechos de la Naturaleza en los países amazónicas, publicado en Los Derechos de la Naturaleza. El futuro es hora, Abya - Yala, pág. 97.

93 Acosta, Alberto, Op. Cit., "Los Derechos de la Naturaleza. Una lectura sobre el derecho a la existencia", pág. 21.

94 Zaffaroni, Raúl, "La Naturaleza con Derechos. De la filosofía a la política", Op. Cit., pág. 82.

95 Acosta, Alberto, "Los Derechos de la Naturaleza, una lectura sobre el derecho a la existencia", Op. Cit., pág. 346.

96 Es revelador el resultado del "EnvironmentalPerfomancelndex", publicado por la Universidad de Yale, disponible en http://epi.yale.edu/dataexplorer/tableofmainresults 
existieron durante milenios en un estado de gracia ambiental, como una especia más entre las demás, en un ecosistema global equilibrado y armonioso"97. Esto se terminó con la Revolución Industrial que modificó esta situación y nos ha puesto a puertas de una crisis ambiental total, para ello usan la ecofilosofía es buscar la "forma en que puede restablecerse el equilibrio para salvar el planeta de su propia aniquilación...". Se sostiene que el problema central es de carácter ideológico, y se refiere a la forma en que entendemos a la naturaleza (el concepto) y el lugar que ocupa el ser humano en ella ${ }^{98}$. No existe acuerdo entre ellos sobre el momento de la modificación de esta posición, para algunos “...ecofilósofos radicales, el gran error fue nada menos que la glorificación de la razón, que empezó en Europa a principios de la Edad Moderna y culminó con la metodología científica contemporánea"99. Sin embargo hay quienes sostienen que esta ruptura se puede encontrar en Platón, otros dicen que en el libro del Génesis o con la agricultura en el Neolítico.

El debate informado inicial, es decir a partir de información, de investigación, de estudios antropológicos con métodos científicos da cuenta que en la premodernidadexistía una actitud "mucho menos benigna ecológica y socialmente" 100 . Afirma que "La tortura de los animales, la opresión a las mujeres a manos de los hombres o la devastación ecológica total (o local) quizá no constituyan manifestaciones universales, pero eran bastante comunes en todas partes. Incluso si nos remontamos al Paleolítico Superior [ . . . ] una buena cantidad de datos sugiere que los seres humanos de aquella época fueron los culpables de la extinción de docenas de especies de grandes mamíferos"|0।. Alan Sokal advierte que actualmente existen datos que no dan cuenta que las extinciones paleolíticas de grandes mamíferos en América y Australia se debieron a la caza humana, a los cambios climáticos y ambientales, o a una combinación de las dos $\operatorname{cosas}^{102}$.

\section{LAS DECISIONES DE LA CORTE CONSTITUCIONAL DEL ECUADOR}

Al 10 de junio del $2018^{103}$ se identificaron 32 decisiones de la Corte Constitucional referidas a los derechos de la naturaleza ${ }^{104}$ en 28 de ellas la Corte se limita a reproducir

97 Ost, Françoise, Naturaleza y Derecho. Para un debate ecológico, Mensajero, Bilbao, 1996, p. 210.

98 Ibíd.

99 Ibíd.

100 lbíd., pp. 217-218.

101 Ibíd., p. 215.

102 Sokal, Alan, Más allá de las imposturas intelectuales, Paidós, Barcelona, 2009, p. 408.

103 Debido al proceso de evaluación de la Corte Constitucional y la cesación de la Corte no existen nuevas sentencias, hasta mayo del 20 I9, en que se desarrolle de alguna forma el tema de los derechos de la naturaleza.

104 Dictámenes: 0 |8-I3-DTI-CC, O|6-I3-DTI-CC, O|4-|4-DTI-CC, No. 003-16-DEE-CC, 00 I-I5-DEE-CC, 00 I-I4-DEE-CC, 02।-10-DTI-CC, 009-I7-DTI-CC, 008-I7-DE- 
los textos constitucionales sin realizar análisis alguno sobre el tema, es a partir de la sentencia N. ${ }^{\circ}$ 065- I 5-SEP-CC de I I de marzo del 2015 (Caso N. ${ }^{\circ}$ 0796- I 2-EP) esta tendencia cambia ${ }^{105}$ al realizar algún esfuerzo argumentativo adicional y toma un giro relevante en otras tres sentencias: No. 166- I5-SEP-CC de 20 de mayo de 2015 (Caso No. 0507-12-EP), No. 218-15-SEP-CC de 9 de julio de 2015 (Caso No. 128 I-12EP), N. ${ }^{\circ} 034-$ I 6-SIN-CC de 27 de abril de 2016 (Caso N. ${ }^{\circ} 00$ I I- I3-IN).

Si bien, en la sentencia N. ${ }^{\circ}$ 065- I 5-SEP-CC ${ }^{106}$ de II de marzo del 2015 (Caso N. ${ }^{\circ}$ 0796- I2-EP), la Corte analiza los derechos de la naturaleza en relación a los impactos en el "bienestar de las personas, comunidades, pueblos, nacionalidades y colectivos", considera que al haber reconocido a la naturaleza como sujeto de derechos está obligada a examinar el uso de los recursos naturales "en beneficio de la sociedad" pero "siempre y cuando se respeten sus ciclos vitales [de la naturaleza] sin atentar contra su existencia, interconexión de los derechos". Según la Corte, es a partir de una interpretación sistemática de la Constitución que incluye la protección de los derechos de la naturaleza, que deben examinarse las sanciones a quienes provoquen un daño a un ecosistema y provoquen cambios "por la tala, quema o acción destructiva, que tenga un impacto adverso cuantificable en la calidad del ecosistema o en alguno de sus componentes, incluyendo sus valores de uso y de su capacidad de apoyar y sostener un balance ecológico viable".

En la sentencia No. 166-I 5-SEP-CC ${ }^{107}$, de 20 de mayo de 2015, la Corte profundiza en el análisis de estos derechos y afirma que la protección de derechos propios de la naturaleza es un cambio de paradigma en el que la "naturaleza, en tanto ser vivo, es considerada un sujeto titular de derechos". Estima que se consagra "una

E-CC. Resoluciones 0567-08-RA, 0242-07-RA, 898-09-RA. Sentencias 0006-10-SEE-CC, 034-16-SIN-CC, I66-I5-SEP-CC, 065-I5-SEP-CC, 218-I5-SEP-CC, 29|-I6-SEP-CC, 002-I6-SAN-CC, 293-I5-SEP-CC, 020-I5-SIN-CC, 007-I5-SIN-CC, 196-I4-SEP-CC, 172-I4-SEP-CC, 0I2-I3-SIN-CC, 0II-I3-SIN-CC, 0I2-I3-SIN-CC, 024-I2-SIN-CC, 017-I2-SIN-CC, 030- I7-SIN-CC, 00I- I7-SCN-CC, 270- I7-SEP-CC.

${ }^{105}$ En el artículo "Los derechos de la naturaleza en la jurisprudencia constitucional ecuatoriana" se identifica de forma incorrecta a la sentencia 2 I 8- I5-SEP-CC de 9 de julio de 2015 como la primera en la que se identifica violaciones a los derechos de la naturaleza. Vid. "Los derechos de la naturaleza en la jurisprudencia constitucional ecuatoriana" de Francisco José Bustamante, publicado en el Observatorio de Justicia Constitucional. http://observatoriojusticiaconstitucional.uasb.edu.ec/articulistas/-/asset_publisher/6iE7o2o3Gu0e/content/los-derechos-de-la-naturaleza-en-la-jurisprudencia-constitucional-ecuatoriana?inheritRedirect $=$ true

106 Una acción extraordinaria de protección presentada por un empresario camaronero en contra de una decisión de la de la Primera Sala de lo Civil y Mercantil de la Corte Provincial de Justicia de Manabí que impedía sus actividades en una zona de manglar.

${ }^{107}$ Esta es una acción extraordinaria de protección para evitar actividad acuícola en una área protegida de la Reserva Ecológica Cayapas Mataje. 
doble dimensionalidad sobre la naturaleza y al ambiente en general, al concebirla no solo bajo el tradicional paradigma de objeto de derecho, sino también como un sujeto, independiente y con derechos específicos o propios".

La Corte considera que esto se debe al cambio de la relación jurídica naturaleza-humanidad en la que se reemplazó en el 2008 una visión biocéntrica en la cual, se prioriza a la naturaleza en contraposición a la "...concepción antropocéntrica en la que el ser humano es el centro y medida de todas las cosas donde la naturaleza era considerada una mera proveedora de recursos". Señala que el fin primordial del Estado es alcanzar el buen vivir o sumak kawsay, siendo en esta concepción trascendental promover un desarrollo social y económico en armonía con la naturaleza. Para la Corte Constitucional las reglas que regulan el "Régimen del Buen Vivir" son las que recogen e incorporan ". .. una serie de instituciones y principios orientados a velar por los derechos de la naturaleza, entre los cuales se destacan, la responsabilidad objetiva y el principio de precaución, la actuación subsidiaria del Estado en caso de daños ambientales, la participación ciudadana, el sistema nacional de áreas protegidas entre otras". La Corte dice que la Constitución, en el artículo 7l, empieza por identificar a la naturaleza con la denominación alterna de Pacha Mama, a la que define "como el lugar donde se reproduce y realiza la vida" y al reconocerle el derecho al respeto integral de su existencia y al mantenimiento y regeneración de sus ciclos vitales, estructura, funciones y procesos evolutivos, dice que "prevalece la protección de la naturaleza tanto en el conjunto de sus elementos (integralidad) como en cada uno de ellos individualmente considerados (ciclos vitales, estructura, funciones y procesos evolutivos)". Se resalta el "rol fundamental" que tienen los ciudadanos en la protección de los derechos de la naturaleza debido a que "gozamos de legitimación activa para representar a la naturaleza cuando sus derechos estén siendo conculcados". Posteriormente analiza el alcance del derecho la restauración que "... implica la recuperación o rehabilitación de la funcionalidad ambiental, de sus ciclos vitales, estructura y sus procesos evolutivos, sin considerar las obligaciones adicionales de carácter económico que el responsable del daño deba cancelar a quienes dependan de los sistemas naturales afectados". Considera que este derecho no se refiere

...a la reparación pecuniaria a favor de las personas perjudicadas, sino a la restitutio in integrum, es decir, a la plena restitución de la naturaleza mediante la reparación de los daños producidos en el medio físico hasta regresar en lo posible el ecosistema original, es decir, la restauración debe estar encaminada hacia el aseguramiento que el sistema natural vuelva a gozar de condiciones que permitan el correcto desenvolvimiento en relación a sus ciclos vitales, 


\section{estructura, funciones y procesos evolutivos ${ }^{108}$.}

Para la Cortede las normas constitucionales se desprende un cambio de concepción que, además de considerar a la naturaleza como sujeto de derechos, "dota de transversalidad sobre todo el ordenamiento jurídico a los derechos reconocidos a la Pacha Mama", por ello señala que "todas las actuaciones del Estado, así como de los particulares, debe hacerse en observancia y apego con los derechos de la naturaleza". La Corte cita a Julio Prieto que considera que existe un "...principio de transversalidad de los derechos de la naturaleza. . . plasmado expresamente en los artículos 83 numeral 6 y 395 numeral 2 de la Constitución". Esta tranversalidad, sostiene la Corte, citando a Prieto,

se aplica no solo específicamente a las políticas en gestión ambiental ni a las obligaciones del Estado para mitigar el cambio climático, sino a las de salud, educación y otras más, dejando reflejar la manifestación de esta transversalidad en un verdadero entramado normativo. (...) En efecto, los derechos de la naturaleza, al igual que los derechos humanos reconocidos en el entramado constitucional -sin perjuicio de los que integran el bloque de constitucionalidad- son derechos constitucionales, y en esa medida deberán ser interpretados y aplicados conforme a la Constitución ${ }^{109}$.

Se esto se deriva la obligación de los órganos judiciales de asegurar la "tutela efectiva de los derechos de la naturaleza, esto es, el respeto integral a su existencia, mantenimiento y regeneración de sus ciclos vitales, estructura, funciones y procesos evolutivos", por ello debe asegurarse

...el estudio de los potenciales impactos que genera en la naturaleza el proceso de producción [en este caso la acuacultura del camarón]..., más aún, cuando en el caso en concreto dicha actividad es realizada dentro de una zona declarada como reserva ecológical10.

La Corte sin aportar sustento alguno dice que la naturaleza es un "ser vivo", no aclara que usa esto como una ficción, asume como un hecho lo que es una creencia y da pasoa una perspectiva "animista".

En la sentencia 2 I8- I5-SEP-CC II', de 9 de julio de 20।5, se replica esta idea

${ }^{108}$ Corte Constitucional sentencia No. 166-I5-SEP-CC.

${ }^{109} \mathrm{lbíd}$.

110 lbíd.

'I' En esta acción extraordinaria de protección se estimó que toda actividad, obra o proyecto que no cuente con el permiso ambiental opera al margen de la ley, actuar sin eso permiso 
Ahora bien, es evidente que la Constitución ecuatoriana tiende a una perspectiva biocéntrica de relación "naturaleza-sociedad" en la medida en que reconoce a la naturaleza como ser vivo y como dadora de vida y por tanto, fundamenta el respeto que le deben los seres humanos en su valoración como ente titular de derechos más allá de su utilidad para las personas. Esto por cuanto, el preámbulo de la Constitución consagra la decisión del pueblo soberano del Ecuador de construir una nueva forma de convivencia ciudadana en diversidad y armonía con la naturaleza para alcanzar el buen vivir, el sumak kawsay a través de celebrar "(...) a la naturaleza, la Pacha Mama, de la que somos parte y que es vital para nuestra existencia".

Tampoco en este caso la Corte aporta razón, argumento o evidencia alguna arribar a esta conclusión, así sin sustentoalguno generaliza estaparticular forma de entender a la naturaleza al conjunto de la sociedad.

En la sentencia 034-16-SIN-CC 112 de 27 de abril de 2016 repite las consideraciones expuestas en las sentencias anteriores y reitera la idea de que "la ruptura del tradicional paradigma de considerar a la naturaleza como un mero objeto de derecho, para pasar a considerarla como un sujeto, en tanto constituye un ser vivo". Eso, afirma la Corte, es una "... evolución respecto del tradicional derecho a un ambiente natural sano, cuyo titular es el ser humano, hacia la protección de la naturaleza como titular independiente de derechos", lo que se constituye en "... un alejamiento de la concepción antropocéntrica clásica, por la cual el ser humano es el centro y fin de todas las cosas y nos acerca a una visión biocéntrica, en la que se reivindica la relación de necesidad del ser humano hacia la naturaleza".

En esta sentencia se extienden todos los principios de aplicación de los derechos a los derechos de la naturaleza, en particular se recuerda que los derechos son de directa e inmediata aplicación, por cualquier autoridad del Estado, por tanto no puede alegarse falta de norma jurídica o exigir requisitos o condiciones para su vigencia y ejercicio. También la Corte considera que los "... derechos de la naturaleza, al igual que el resto de derechos consagrados en la Constitución son inalienables, irrenunciables, indivisibles, interdependientes y de igual jerarquía".

\section{El uso de la categoría derechos para aplicarla a la naturaleza y las decisiones de}

ambiental constituye una vulneración a los derechos de la naturaleza contenidos en el artículo 7I de la Constitución.

112 Esta sentencia también se dictó dentro de una acción extraordinaria de protección y se refiere a un acuerdo ministerial por el que se permite la explotación minera en una zona protegida, estimándose que existe una vulneración de zonas naturales e hídricas, y con ellos los derechos de la naturaleza, la decisión de Ministerio del Ambiente al permitir la explotación en aquella zona. 
LOS DERECHOS DE LA NATURALEZA EN LA CONSTITUCIÓN ECUATORIANA DEL 2008: ALCANCE, FUNDAMENTOS Y RELACIÓN CON LOS DERECHOS HUMANOS

\section{la Corte Constitucional ecuatoriana}

Existen críticas significativas a la idea de que la asignación de derechos a la naturalezaproviene de que esta sea un ser vivo ya que no existe evidencia alguna sobre esto, incluso en las versiones de la Gaia de Lovelock ${ }^{1 / 3}$ no se afirma que la Tierrasea un ser vivo. No me detendré en aquellas críticasque consideran que la categoría derechos es atribuible a quienes tienen capacidad de raciocinio moral o conciencia propia (una idea kantiana) o "poderes morales", la capacidad de concebir el bien y la capacidad de tener sentido de la justicia en un grado mínimo (una idea de Rawls); tampoco revisaré las críticas que existen desde las distintas vertientes del iusnaturalista, sea teocrático o racionalista, por considerar que se excluye del reconocimiento de derechos a sujetos no humanos (no obstante que en muchas ocasiones se fundamentan los derechos de la naturaleza en consideraciones espirituales similares).

No es posible en este trabajo presentar las múltiples perspectivas y definiciones que existen sobre los derechos ${ }^{1 / 4}$, con una finalidad definitoria considero a un derecho como una pretensión justificada. La justificación de la pretensión es una norma legal resultante de una fuente aceptada en un ordenamiento jurídico específico. Este derecho contiene dos elementos, uno subjetivo que es la pretensión, y el otro objetivo, la norma ${ }^{1 / 5}$. En ese sentido, siguiendo a Guastini, los derechos son relativos a una norma o a un sistema de

${ }^{113}$ Es relevante la explicación de Lynn Margulis sobre el uso del concepto "organismo en la obra de James Lovelock "Al darle al planeta el nombre de la diosa griega, Lovelock, en un verdadero acto de bautismo, convirtió su idea en memorable, tanto para la ciencia como para sus enemigos. Logró personalizar el objeto de estudio y centrar la atención de sus colegas en sus características sobresalientes. En la mente de muchos, 'Gaia' quedó reducida a un eslogan: 'la Tierra es un organismo gigante', de hecho un organismo «femenino». ¿Cómo -protestábamos ante Lovelock- podría ser la Tierra un 'organismo', cuando ningún organismo puede vivir de sus propios residuos? ¿Por qué insistes en promover la imagen de la Tierra como un ser único y gigantesco -le recriminábamos- alejándote de la ciencia y atrayendo hacia a (sic) ti la potencial enemistad de respetables colegas? ¿Por qué no decir que Gaia es un ecosistema gigante, que reconoce la pluralidad de los seres que lo componen, le sugeríamos. Pero él insistía. El término «ecosistema» le parece engorroso, difícil de definir y completamente opaco para quienes no estén familiarizados con la ecología. Es más, se atreve a defender su metáfora de la diosa. «Si consigo que piensen en la Tierra como en un ser vivo -explica- aprenderán a respetarla y a amarla. Si el planeta no es más que un montón de rocas, no hay inconveniente en darle puntapiés y maltratarlo. A nadie le importa. Por supuesto, Gaia no es un organismo único ni ninguna diosa, pero está viva y merece nuestra comprensión y nuestra reverencia". Lynn Margulis y DorionSagan, "Captando genomas. Una teoría sobre el origen de las especies”, Kairos, Barcelona, 2003, pág. 183.

${ }^{114}$ A propósito de estas discusiones se puede consultar el texto de Santiago Nino "Los derechos", publicado en el libro recopilatorio "Una teoría de la justicia para la democracia", Siglo XXI, Buenos Aires, 2014, pp. 199-226, y el de Ricardo Guastini "Derechos", publicado en el libro recopilatorio "Distinguiendo", Gedisa, Barcelona, 1999, pp. 179-192.

${ }^{115}$ Guastini,Ricardo, Distinguiendo, Gedisa, Barcelona, 1999, pp. | 8 | - 182. 
normas que lo confiere, en este caso interesa los sistemas normativos jurídicos positivos.

Una dimensión distinta del debate son los discursos justificatorios para reconocer tal o cual derecho, recordando que algunas teorías jurídica se considera que los derechos eran exclusivamente atribuibles a los seres humanos, en cuanto estos están dotados de algunos atributos como la autonomía, la capacidad de expresar voluntad o una dignidad considerada como intrínseca.

Particularmente relevante en el Ecuador es el concepto dignidad debido a que la Constitución del 2008 lo usa como una fuente de derechos extranormativa, al establecer que los derechos reconocidos en la Constitución y en los instrumentos internacionales de derechos humanos "no excluirá los demás derechos derivados de la dignidad de las personas, comunidades, pueblos y nacionalidades, que sean necesarios para su pleno desenvolvimiento"16".

Este guiño iusnaturalista de la Constituyente cierra la puerta al reconocimiento de cualquier otro derecho a la naturaleza que no esté expresamente reconocido en el texto constitucional, debido a que la norma que reconoce los derechos determina este límite de forma expresa "La naturaleza será sujeto de aquellos derechos que le reconozca la Constitución $117 "$.

Es claro que las justificaciones para reconocer jurídicamente un derecho van más allá de la propia norma, su aprobación obedece a ciertas "razones" que permiten interpretar el alcance o cobertura de un derecho. Es necesario recordar que todas las teorías justificatorias de derechos específicos han sido pensadas en relación a los seres humanos y por ellono puede extenderse de forma automática para justificar los derechos de la naturaleza; esto tiene dos consecuencias obvias, los derechos de la naturaleza no pueden en caso alguno ser los mismos que se reconocen a los seres humanos y los derechos reconocidos a la naturaleza están limitados a las normas que los contienen (algo que es común a los derechos humanos). Los derechos de la naturaleza tienen un alcance claramente limitado en Ecuador, se reconoce derechos a la naturaleza como un todo y no a sus partes que mantienen su estatus jurídico específico. A partir de esto no puede colegirse que ha dado origen a que los animales, los árboles, las montañas o los ríos sean titules individuales de derechos en Ecuador.

En este sentido el alcance del reconocimiento ecuatoriano es similar a lo sucedido en otrospaísesenlosqueelreconocimientojurisprudencial, comoenelcasodeColombia "18; o una ley en el caso de Nueva Zelanda! ${ }^{19}$, se limita a la entidad natural a la que se

\footnotetext{
116 Numeral 7 del artículo I I que contiene los principios para el ejercicio de los derechos.

117 Inciso final del artículo 10 "Titulares de derechos".

${ }^{118}$ Corte Constitucional colombiana, sentencia T-622 de 10 de noviembre del 2016.

119 Nueva Zelandia declaró, por medio de una ley aprobada el I 5 de marzo del 2017, al rio Whanganui como una persona en los mismos términos que una persona jurídica. El antecedente es un acuerdo alcanzado con el pueblo Whanganuiiwi en el año 2012 con las Corona,
} 
asignaron los derechos, los ríos o la selva; o el caso de la República Argentina a los orangutanes $^{120}$ o chimpancés ${ }^{121}$.

Los derechos reconocidos a la naturaleza o a sus elementos no son intercambiables, tampoco es posible hacerlo con los principios relacionados con los derechos humanos (de forma individual o como parte de un pueblo), ya que los derechos de la naturalezaestán limitados al alcance de la norma que otorga el derecho. Es claro que para la interpretación y aplicación de los derechos de la naturaleza deben observarse los principios constitucionales sobre los derechos en lo que proceda ${ }^{122}$, por tanto no puede trasladarse todos los principios de aplicación y es especialmente equivocada es la afirmación de que derechos de la naturaleza y derechos de los seres humanos son equiparables ${ }^{123}$.

La idea primigenia de Stone era dotarle de representación legal autónoma a la naturaleza, de manera que sea posible comparecer en su defensa sin tener que mostrar interés directo en el litigio o daños a personas o comunidades concretas. La ampliación del alcance de los derechos, más allá de la personalidad jurídica, es un resultado directo de las visiones ecocéntricas.

Como se dijo no pueden reconocerse los mismos derechos de los seres humanos a la naturaleza y los derechos reconocidos dependen de las normas que atribuyen ese derecho, lo que implica identificar a cada entidad protegida y con ello a cada especie o ecosistema concreto y la perspectiva de las comunidades involucradas en el reconocimiento normativo de acuerdo a la vía que se escoja. Como se adelantó en el caso del rio Atrato se establecen derechos "bioculturales ${ }^{124}$,en la normativa

los intereses del río serán representados por dos funcionarios, uno de los Whanganuiiwi y el otro de la Corona. http://www.nzherald.co.nz/nz/news/article.cfm?c_id=I\&objectid $=|| 8 \mid 8858$.

${ }^{120}$ Concesión de un recurso de habeas corpus a un orangután por Sala Il de la Cámara Federal del Casación Penal de la República Argentina, el 18 de diciembre de 2014.

121 Sentencia de 3 de noviembre del 2016, Tercer Juzgado de Garantías de Mendoza. Expediente No. P-72.254/I5, "Presentación efectuada por la A.F.A.D.A respecto del chimpancé "Cecilia-Sujeto no humano".

122 Inciso segundo del art. 7 I de la Constitución.

${ }^{123}$ Suárez ,Sofía, Efectivización de los derechos de la naturaleza: evolución jurisprudencial, publicado en el Boletín del Centro Ecuatoriano de Derecho Ambiental, 2102 , p. 2. Disponible en http://www.cadhu.org/wp-content/uploads/20 I8/04/EFECTIVIZACION-DE-LOS-DERECHOS-DE-LA-NATURALEZA.-Autora.-Sofia-Suarez.pdf .

${ }^{124}$ Los derechos bioculturales (biocultural rights) son “. . . un intento de conciliación en la relación especial que tienen los pueblos indígenas, tribales y de otras colectividades étnicas con el cuidado especial o stewardship de la naturaleza y sus recursos". Los derechos bioculturales se definen como los "derechos que tienen las comunidades étnicas a administrar y a ejercer tutela de manera autónoma sobre sus territorios -de acuerdo con sus propias leyes, costumbres- y los recursos naturales que conforman su hábitat, en donde se desarrolla su cultura, sus tradiciones y su forma de vida con base en la especial relación que tienen con el medio ambiente y la biodiversidad". 
neozelandesa sobre al parqueTe Urewara ${ }^{125} y$ al rio Whanganuil ${ }^{126}$ se da a partir de los derechos de los pueblos que allí habitan, reconociendo su cosmovisión.

Establecer los límites de la protección en cada caso, de cada ecosistema, demanda la intervención de la ciencia occidental en una obvia interrelación con los conocimientos de cada pueblo o comunidad, pero no siempre coinciden los saberes ancestrales con los datos aportados por la ciencia, especialmente con los intereses políticos y económicos en juego lo que es una puerta a los conflictos por la disputa para determinar y la necesidad de determinar "quién habla por la naturaleza'127".

Esto lleva a otra consideración ies posible identificar intereses propios de la naturaleza?, si esto es posible a quién le corresponde determinarlos. Este debate lleva directamente a la fundamentación de los derechos y la imposibilidad de establecer intereses en las cosas, los objetos y seres vivos que no pueden expresar ese interésm en las versiones esencialistas del biocentrismo la respuesta es que existe un interés que cubre al todo, porque cada parte de ese todo (la Gaia, la Pachamama), incluidos los seres humanos, cumplen un papel en la realización de un objetivo ${ }^{128}$.

En términos concretos, en la mirada de uno de los objetivos señalados para re-

Desde esta perspectiva, para la Corte, existe una "...vinculaciónintrínseca entre naturaleza y cultura, y la diversidad de la especie humana como parte de la naturaleza y manifestación de múltiples formas de vida [...]. la conservación de la biodiversidad conlleva necesariamente a la preservación y protección de los modos de vida y culturas que interactúan con ella".

125 Ley Te Urewara de 2014, disponible en http:/www.legislation.govt.nz/act/public/20 |4/005 I/latest/DLM6 |83609.html. En esta ley se reconoció la personalidad jurídica al parque Te Urewara al que no se considera de propiedad del Estado o de la tribu Tuhoe. Su administración corresponde al pueblo y al gobierno con el fin de preservar los sistemas ecológicos ancestrales y la biodiversidad del parque se obligan a erradicar plantas y animales introducidas, además de reconocer la contribución de los Te Urewara en la conservación del parque. Se lo reconoce como un lugar de "valor espiritual", que debe considerarse un lugar con un "valor intrínseco", que es valioso tanto por sus entorno natural, por su bosque primario, los sistemas ecológicos indígenas, su biodiversidad, su patrimonio histórico y cultural, su importancia científica y por ser un lugar de recreación al aire libre y de reflexión espiritual. Esta ley es parte de los acuerdos alcanzados entre el gobierno de Nueva Zelanda y la tribu Tahoe, que perdió los derechos sobre su territorio a partir del Tratado de Waitangi de 1840 que la tribu no firmó.

126 Whanganui River Claims Settlement, disponibleenhttp://www.legislation.govt.nz/bill/government/2016/0 129/latest/whole.htmI\#DLM6830857. Se reconoce la personalidad del rio Whanganui y sus afluentes se dio bajo los términos del acuerdo suscrito entre el gobierno y el pueblo Maorí, los derechos se otorgan a los ríos y sus afluentes se lo hace al considerar que es un todo indivisible por considerar que existe una "interconexión intrínseca entre el río y quienes habitan alli"

${ }^{127}$ Burton, Peter, ob. cit., p. 79.

${ }^{128}$ Ob. cit., p. 81 . 
conocer derechos a la naturaleza como una mejora de la protección ambiental ${ }^{129}$ John Livingston ${ }^{130}$ considera que los derechos son en realidad instrumentos políticos, herramientas, cuando el ser humano trata a la naturaleza como su igual la "domestica" y esto conlleva una suerte de "humanización" que trae aparejado el peligro de desgastar el poder de los derechos con su proliferación y ampliación. Únicamente el comportamiento humano puede ser regulado, cuando se usa un enfoque de derechos se asume la existencia de una contrapartida, las obligaciones que corresponden a otro sujeto o sujetos, estas se establecen en relaciones específicas en la que cada parte cumple un rol diferente. Otorgarle derechos a la naturaleza implica una interacción con los seres humanos, porque los derechos están asociados a obligaciones de acción o abstención humana, son los humanos los que hablan en su nombre, por tanto esto diferirá de la perspectiva que se tenga sobre la naturaleza, sus intereses e interacciones con los humanos.

Considerar a la naturaleza como un ser vivo, dotarle de alguna forma de conciencia, asignarle una condición de deidad no se compadece con el principio de interculturalidad, el reconocimiento de pluralidad valorativa y el respeto a las diferentes perspectivas de una sociedad democrática y plural. Una cosmovisión particular del mundo que implica una serie de creencias compartidas por un grupo, que le asignan una condición metafísica a la naturaleza, como una suerte de religión sustentada en el animismo, una imposición de un elemento de una identidad particular al conjunto de la sociedad.

Desde una perspectiva de derechos humanos es imprescindible reconocer que para los pueblos ancestrales"... La tierra significa más que meramente una fuente de subsistencia para ellos; también es una fuente necesaria para la continuidad de la vida y de la identidad cultural [...]. Las tierras y los recursos del pueblo... forman parte de su esencia social, ancestral y espiritual..."; que la cultura de las comunidades indígenas corresponde a una forma de vida particular de ser, ver y actuar en el mundo, constituido a partir de su estrecha relación con sus territorios tradicionales y los recursos que allí se encuentran, no sólo por ser estos su principal medio de subsistencia, sino además porque constituyen un elemento integrante de su cosmovisión, religiosidad $y$, por ende, de su identidad cultural...131".

La Corte Interamericana de Derechos Humanos a propósito de la posible imposición de ciertas creencias específicas al conjunto de la sociedad ha sido clara. En el

${ }^{129}$ Elizalde Hevia, Antonio, "Aportes sobre los Derechos de la Naturaleza", publicado en "Derechos de la Naturaleza. El futuro es ahora", Alberto Acosta y Esperanza Martínez (compiladores), editorial Abya - Yala, Quito, 2009, pp. 70 -7I.

${ }^{130}$ Citado por Peter Burdon, ob. cit., p. 79.

131 Caso del Pueblo Saramaka. Vs. Surinam. Excepciones Preliminares, Fondo, Reparaciones y Costas. Sentencia de 28 de noviembre de 2007, párr. 82; y, Caso Comunidad Indígena Sawhoyamaxa Vs. Paraguay. Fondo, Reparaciones y Costas. Sentencia de 29 de marzo de 2006, párr. 118. 
caso Artavia Murillo consideró que

Algunos de estos planteamientos [que estiman que los óvulos fecundados son una vida humana plena] pueden ser asociados a concepciones que le confieren ciertos atributos metafísicos a los embriones. Estas concepciones no pueden justificar que se otorgue prevalencia a cierto tipo de literatura científica al momento de interpretar el alcance del derecho a la vida consagrado en la Convención Americana, pues ello implicaría imponer un tipo de creencias específicas a otras personas que no las comparten ${ }^{132}$.

A partir de esto es posible afirmar -mutatis mutandis- que extender una perspectiva metafísica, como la que asigna a la naturaleza la condición de ser vivo, a toda la sociedad es inaceptable ya que es una imposición de una creencia particular al todas las personas que no comparten esta perspectiva metafísica.

\section{REFERENCIAS}

ACOSTA, Alberto. Los Derechos de la Naturaleza. Una lectura sobre el derecho a la existencia, Abya-Yala, Quito, 201 I.

ALTMANN, Philipp. El movimiento indígena ecuatoriano y su discurso - Un análisis de discurso centrado en los conceptos, conferencia presentada en el marco de la I6th International ConferenceontheHistory of Concepts, Bilbao y San Millán de la Cogolla (La Rioja), 29 a 3 I de agosto del 2013 . Disponible en https://www.academia. edu/49|2862/El_movimiento_ind\%C3\%ADgena_ecuatoriano_y_su_discurso_Un_an\%C3\%Allisis_de_discurso_centrado_en_los_conceptos .

Asamblea Constituyente del Ecuador. Informe de Mayoría sobre los Derechos de la Naturaleza, Mesa No. I de Derechos Fundamentales y Garantías Constitucionales, 2008.

BEDÓN, René. Contenido y aplicación de los derechos de la naturaleza, publicado en lus Humani, volumen 5, 2016

BEDÓN, René. "Aplicación de los derechos de la naturaleza en Ecuador", publicado en la Revista Veredas de Direito, volumen I4, enero-abril 2017.

BORJA ORTIZ, Andrés. Derechos de la naturaleza, publicado en Nuevas instituciones del Derecho constitucional ecuatoriano, Tomo I, INREDH, Quito 2008.

\footnotetext{
${ }^{132}$ Corte Interamericana de Derechos Humanos, caso Artavia Murillo y otros ("Fecundación in vitro") vs. Costa Rica, sentencia de Excepciones Preliminares, Fondo, Reparaciones y Costas de 28 de noviembre de 2012, párr. 185.
} 
LOS DERECHOS DE LA NATURALEZA EN LA CONSTITUCIÓN ECUATORIANA DEL 2008: ALCANCE, FUNDAMENTOS Y RELACIÓN CON LOS DERECHOS HUMANOS

BURDON, Peter. Rights of Nature: reconsidered, University of Adelaida, Law School, Reasearch Paper No. 2011-010, 201।, p. 74. Disponible en https://papers.ssrn. com/sol3/papers.cfm?abstract_id $=1709015$.

CAFFERATTA, Néstor y Morello, Augusto. La Sociedad y la Naturaleza como Sujetos de Derecho, Revista el Derecho, Número monográfico, Tomo 212.

CONAIE, Las nacionalidades indígenas del Ecuador: nuestro proceso organizativo, 1992. Disponible en http://www.fes-ecuador.org/fileadmin/user_upload/ pdf/0 I 2 1\%20NACINDI986_0121.pdf.

Corte Interamericana de Derechos Humanos, caso del Pueblo Saramaka. Vs. Surinam. Excepciones Preliminares, Fondo, Reparaciones y Costas. Sentencia de 28 de noviembre de 2007, párr. 82; y, Caso Comunidad Indígena Sawhoyamaxa Vs. Paraguay. Fondo, Reparaciones y Costas. Sentencia de 29 de marzo de 2006.

Corte Interamericana de Derechos Humanos, caso Artavia Murillo y otros ("Fecundación in vitro") vs. Costa Rica, sentencia de Excepciones Preliminares, Fondo, Reparaciones y Costas de 28 de noviembre de 2012.

Corte Constitucional colombiana, sentencia T-622 de 10 de noviembre del 2016.

Diamond, Jared, Colapso, Debate, Bogotá, 2006.

ELIZALDE Hevia, Antonio. "Aportes sobre los Derechos de la Naturaleza", publicado en "Derechos de la Naturaleza. El futuro es ahora", Alberto Acosta y Esperanza Martínez (compiladores), editorial Abya - Yala, Quito, 2009.

ESTERMANN, Josef y Peña, Josef. Filosofía Andina, IECTA-CISA, Cuadernos de Investigación en Cultura y Tecnología Andina No. 12, Iquique, 2004.

GUASTINI, Ricardo. Distinguiendo, Gedisa, Barcelona, 1999.

GUDYNAS, Eduardo. Derechos de la naturaleza. Ética biocéntrica y políticas ambientales, Abya-Yala, Quito, 2016.

GUDYNAS, Eduardo. Aportes sobre los Derechos de la Naturaleza, publicado en Derechos de la Naturaleza. El futuro es ahora, Alberto Acosta y Esperanza Martínez (compiladores), editorial Abya - Yala, Quito, 2009.

HÖFFE, Otfried. Animal Morale, publicado en "El proyecto político de la modernidad”, Fondo de Cultura Económica, México, 2008.

HOYOS Castañeda, Ilva. La persona y sus derechos, Temis, Bogotá, 2000. 
LINZEY, Thomas Alan. Aportes sobre los Derechos de la Naturaleza, publicado en Derechos de la Naturaleza, Acosta, Alberto y Martínez, Esperanza (compiladores), Abya-Yala, Quito, 2009.

LOVELOCK, James. Las edades de Gaia. Una biografía de nuestro planeta vivo, Tusquets, Barcelona, 2000.

LLASAG Fernández, Raúl. "Los Derechos de la Naturaleza y la Naturaleza de sus Derechos", Ministerio de Justicia y Derechos Humanos, Quito, 20 I I.

MARTíNEZ, Esperanza y Acosta, Alberto. Los Derechos de la Naturaleza como puerta de entrada a otro mundo posible, publicado en la Revista Direito\& Praxis, Rio de Janeiro, Vol. 08, N. 4, 2017, p. 2927-296I. Disponible en línea en http://www. scielo.br/pdf/rdp/v8n4/2179-8966-rdp-8-4-2927.pdf .

MANN, Charles C. I49INew revelations of the americas before Columbus Random House, New York, 2005.

MARGULIS, Lynn; Sagan, Dorion. Captando genomas. Una teoría sobre el origen de las especies, Kairos, Barcelona, 2003.

MOLINA-ROA, Javier. La irrupción del biocentrismo jurídico. Los derechos de la naturaleza en América Latina y sus desafíos, publicado en la Revista Ambiente y Sostenibilidad, 2016.

NINO, Santiago. "Los derechos", publicado en el libro recopilatorio "Una teoría de la justicia para la democracia", Siglo XXI, Buenos Aires, 2014.

OST, Françoise. Naturaleza y Derecho. Para un debate ecológico, Mensajero, Bilbao, 1996.

ROSZAK, Theodore. Where the Wastelend Ends: Politics and Trascendence in Postindustrial Society, Faber and Faber, Londres, 1973.

SÁNCHEZ-PARGA, José. Alternativas virtuales vs. cambios reales, CAAP, Quito, $20 \mid 4$.

SERRANO P., Vladimir, Hacía la formulación de un derecho ecológico, publicado en Derecho, ecología y sociedad, compilado por Vladimir Serrano, CEDECO, Quito, 1994.

SIMON C., Farith. "Derechos de la naturaleza: ¿innovación trascendental, retórica jurídica o proyecto político?, publicado en Revista luris Dictio delColegio de Jurisprudencia Universidad San Francisco de Quito, Volumen I5, enero 2013.

SINGER, Peter, Desacralizar la vida humana. Ensayo de Ética, Catedra, Madrid, 2003. 
SOKAL, Alan. Más allá de las imposturas intelectuales, Paidós, Barcelona, 2009, p. 408. Lewis, Martin W., Radical environmental philosophy and the assault on rason, publicadoenThe Flight fron Science and Reason, Gross, Levitt y Lewis (editores), John Hopkins University Press, Annals New York Academy of Science, 1996.

STERNÄNG, Märta. A power analysis of the Rights of nature in Ecuador, tesis de maestría, Stockholm Resilience Centre, Stockholm University, 2018.

STONE, Christopher. Should Trees Have Standing?-Towards Legal Rights for Natural Objects, Southern California Law Review, 1972.

STUTZIN, Godofredo. La doble personalidad del derecho ambiental, Ambiente y Recursos Naturales". Revista de derecho, política y administración, 1986.

TANASESCU, Mihnea. Therights of nature in Ecuador: themaking of an idea, publicado en la revista International Journal of EnvironmentalStudies, volumen 70, 20 I3, número 6.

TOLEDO, Víctor. Utopía y Naturaleza. El nuevo movimiento ecológico de los campesinos e indígenas de América Latina, publicado en la Revista Nueva Sociedad, noviembre-diciembre 1992.

WATSON, Peter. La edad de la nada, Crítica, Barcelona, 20 I 5.

WILSON, Edward Osborne y Kellert, Stephen. The Biophilia Hypothesis, Island Press, Washington D.C., 1993.

Whanganui River Claims Settlement, disponibleenhttp://www.legislation.govt.nz/bill/ government/20 I6/0 I29/atest/whole.html\#DLM6830857 .

ZAFFARONI, Raúl Zaffaroni. "La Naturaleza con Derechos. De la filosofía a la política" de Ediciones Abya-Yala, Quito, 20II.

ZAFFARONI, Raúl. "La Naturaleza con Derechos. De la filosofía a la política" de Ediciones Abya-Yala, Quito, 20II.

ZAFFARONI, Raúl. "La Naturaleza con Derechos. De la filosofía a la política" de Ediciones Abya-Yala, Quito, 20II.

Recebido em: 07/05/2019

Aprovado em: 05/06/2019 
